\title{
Effect of SSSC-based SSR controller on the performance of distance relay and adaptive approach using synchronized measurement
}

\author{
D. Koteswara Raju ${ }^{1}$, Arvind R. Singh ${ }^{2}$, Abhishek Kumar ${ }^{1}$, Mohan. P Thakre ${ }^{3}$, Ramesh C. Bansal ${ }^{2}$ \\ ${ }^{1}$ Electrical Engineering Department, VNIT, Nagpur, India. \\ ${ }^{2}$ Department of Electrical, Electronics and Computer Engineering, University of Pretoria, South Africa. \\ ${ }^{3}$ College of Electrical Engineering, Zhejiang University, China. \\ ${ }^{4}$ Electrical Engineering Department, VPKBIET, Baramati India. \\ ${ }^{*}$ Corresponding author E-mail: eswaar.raju@ gmail.com
}

\begin{abstract}
The use of series compensation in transmission line with capacitors may results the new problems like torsional oscillations in shaft sections of turbine-generator due to subsynchronous resonance (SSR), when system frequency matches with any one of torsional mode frequency of shaft system during fault or disturbances occurs in the transmission line. The subsynchronous current due to SSR during fault also affects the reach of a distance protection system. The diminution of SSR is enhanced by series voltage injection in to the power transmission line with static synchronous series compensator (SSSC) from the knowledge of subsynchronous components, extracted from the system. The use of SSSC in transmission line reduces the subsynchronous oscillations but it adversely affects the distance protection system leads to imprecise assessment of fault location i.e. over or under-reach. This paper investigates the SSR mitigation in presence of SSSC and its effect on distance protection scheme. A new approach is proposed for mitigating the problems associated with distance protection by using the synchrophasor measurement. The entire study of simulation is investigated by using a 48-pulseSSSC carried out with Bergeron model of transmission line in PSCAD. The simulation results represents that the suggested adaptive scheme is truthful, reliable and secure with change in compensation level of SSSC.
\end{abstract}

Key words- Adaptive distance relay, Distance relay, Phasor measurement unit (PMU), SSR, SSSC, voltage source converter (VSC).

\section{INTRODUCTION}

Series capacitor compensation is most widely used from past decades in transmission lines to partially cancel out a part of reactance of line impedance to improve the ability of transmitted power, load sharing between parallel lines and enhance the stability limits of long 
transmission lines $[1,2]$. Nevertheless, the incorporation of series compensation in the line can produce oscillations in the shaft system with the frequency which is usually less than the system frequency i.e. subsynchronous resonance (SSR), completely damages the entire shaft system. If the complement frequency (system frequency - resonant frequency) of the system coincides with any of the mode frequency of the T-G shaft system, the oscillations are drastically excited with fault or disturbance in the series compensated transmission line [3, 4].The production of subsynchronous current due to SSR might badly affect the reach of the distance protection scheme. The increase in the level of series compensation, the effect becomes more worsen. Subharmonics of lower frequency can affect the relay reach as more as compared to higher subharmonics [5].

With the advent of power electronic devices with digital control, new development in Flexible AC transmission devices (FACTS) like TCSC- thyristor controlled series capacitor, SSSC and STATCOM-statics synchronous series compensator are achieved and the research in this area is most attractive at present days [6]. With reference to recent literature, variety of research works has been proposed by the researchers to bypass the issue of SSR using FACTS devices [7]. Regardless of solution, the major complexity is that, how fast the control strategy precisely mitigates the subsynchronous oscillations from the transmission line and further an appropriate protection system should also be designed to avoid turbine shaft damage due to SSR [8].The problem of SSR can be mitigated by series compensation which consists of passive components and SSSC. Ref [9], [10] addresses the damping of SSR using PI controller based SSSC. The injection of voltage of subsynchronous frequency component in series with current of subsynchronous component to damp out SSR is proposed in [11]. In ref. [12-14] the mitigation of SSR is achieved by using FACTS devices with fractional-order PI controller in the control circuit. However, proper control strategy with fast response and robust performance is mandatory and it should be further investigated.

The insertion of devices in power system, such as FACTS leads to new issues in the area of transmission line protection. These devices are most frequently used in power systems because of its fast response time, line impedance, load currents and system power angle are also changed rapidly. Therefore, it is highly significant for a protection engineer to consider and investigate these types of changes in power system. The distance protection relays are most frequently used because of its ease in operating principle and potential to work autonomously under adverse situations for primary protection in high voltage (HV) lines [15, 
16]. Due to the existence of FACTS controllers, the distance relay scheme may not operate correctly and will not able to protect the transmission line. The inappropriate functioning of distance relay causes false tripping and diminishes the consistency and system security but can also instigate the blackouts [17-20].

The variation in distance protection is depends on the type of FACTS device which is used for particular application and its position in the power system. The effect on distance protection of transmission lines with different types of FACTS controllers have been reported in [17-21]. The STATCOM and SVC have an effect on the distance relays with regard to phase selection, measurement of impedance and time of operation, may cause over or under-reach [17-19]. The action of the voltage source converter (VSC) based STATCOM on multiline, increase the resistance to reactance ratio of line, which leads to the impedance relay under-reaching, but no counter measures were not found for zone protection [19], [20]. The work made in [21] provides a fruitful contribution towards the calculation of apparent impedance of distance relay for series devices, viz., TCSC, and SSSC; though, it did not considered the procedure for computing the apparent impedance in case of transmission line consists of series and shunt FACTS controllers. Ref [22-24] addresses the associated problems of shunt/series compensation on distance protection of transmission lines with remedies. The work in [25] made useful techniques about mitigation of shunt FACTS on relay were implemented in real time digital simulator and suggested modifications to the channel aided distance protection scheme. The phasor measurement unit (PMU) provides variety of applications that uses synchrophasors measurements for functional decision-making. Several applications of these are includes security assessment, state estimation, adaptive relaying, control, etc. [26-28]. The work in [29] outline the problems associated with conventional distance protection and proposed the steady state based modified quadrilateral distance relay. But the fixed setting will not work for transient conditions and varying injection of SSSC which is one of the major concern. Similar work is reposted in work [30], but the solution is for severe fault conditions and steady state characteristics. The work presented in [31] give the solution based on digital protection technique utilizing the apparent impedance trip characteristics with SSSC in steady state analysis and the trip boundaries have been considered as new relaying scheme. But the problems associated with the distance based protection remains same and need improvement in its characteristics based on the value of SSSC injection. The active power based protection scheme is presented as a potential solution for SSSC compensated transmission line with no 
suggestion or mitigation of distance based scheme which in require more emphasis to provide the solution for improvement in distance based protection scheme.

The main objective of this research paper is to mitigate the issues of subsynchronous resonance with SSSC and its effect on distance protection of transmission line without sacrificing its security. To improve the performance of distance protection without losing its security, first the behaviour of distance relay is analysed through the help of sequence components with SSSC placed at middle of transmission line. The insertion of SSSC adds corresponding impedance in the fault loop, based on the voltage injected by SSSC. The impedance due to SSSC compensates the calculated impedance due to fault at relay point. The error produced by the calculated compensated impedance in the measurement of actual impedance can be nullified at relay point using proposed algorithm with the support of synchronized measurement. Simulations are made to prove the robustness of the algorithm by comparing the proposed algorithm with the traditional algorithms.

The organization of this research article is given as: Section 2 introduces the study system model with subsynchronous component based SSSC. The estimation of subsynchronous component of current and voltage which is useful to know the value of series injected voltage in to the line using SSSC by means of subsynchronous component controller is presented in Section 3. Section 4 describes the mathematical analysis of distance protection scheme with SSSC placed at middle of transmission line to mitigate SSR and this analysis is useful to resolve the errors present in distance protection with SSSC. Moreover, the section 5 explains the complete idea of synchronized measurement based adaptive mho relay setting. In section 6, simulation results of SSR mitigation and transmission line distance protection scheme with adaptive mho relay setting in presence of SSSC are described. Finally the conclusion of proposed research work is given in section 7 .

\section{SYSTEMMODEL WITH SSR (SSSC) CONTROLLER}

The study system model for this research work consists of two generators connected through single transmission line with different types of faults, location of fault and for different loading conditions [18, 19]. Figure 1 shows the one line diagram of system under consideration and is modelled in PSCAD as a Bergeron model using the transmission line structural data. Appendix A determines the tower configuration of transmission line, parameters of conductor and source data.Figure1 illustrates the location of relay which is at 
bus A. Subsynchronous component based SSSC is connected at middle of the transmission line-1 to mitigate SSR. An assumption is made that a GPS based synchronized measurement is existing on SSSC bus and relaying bus. The data transmission is obtained with the help of an optical fiber. Therefore, the compensated current data of instantaneous time stamped is accessible at relaying bus with no delay [26-28].

The voltage of generator and grid current is denoted byv $\mathrm{s}_{\mathrm{s}}$ and $\mathrm{i}$ and series voltage injected by SSSC is $\mathrm{V}_{\text {se. }}$. The mitigation of SSR with classical control is that, the generated voltage of fundamental frequency component by the fixed capacitor bank is to be neutralized by generating complementary component of voltage using series converter [9-13].

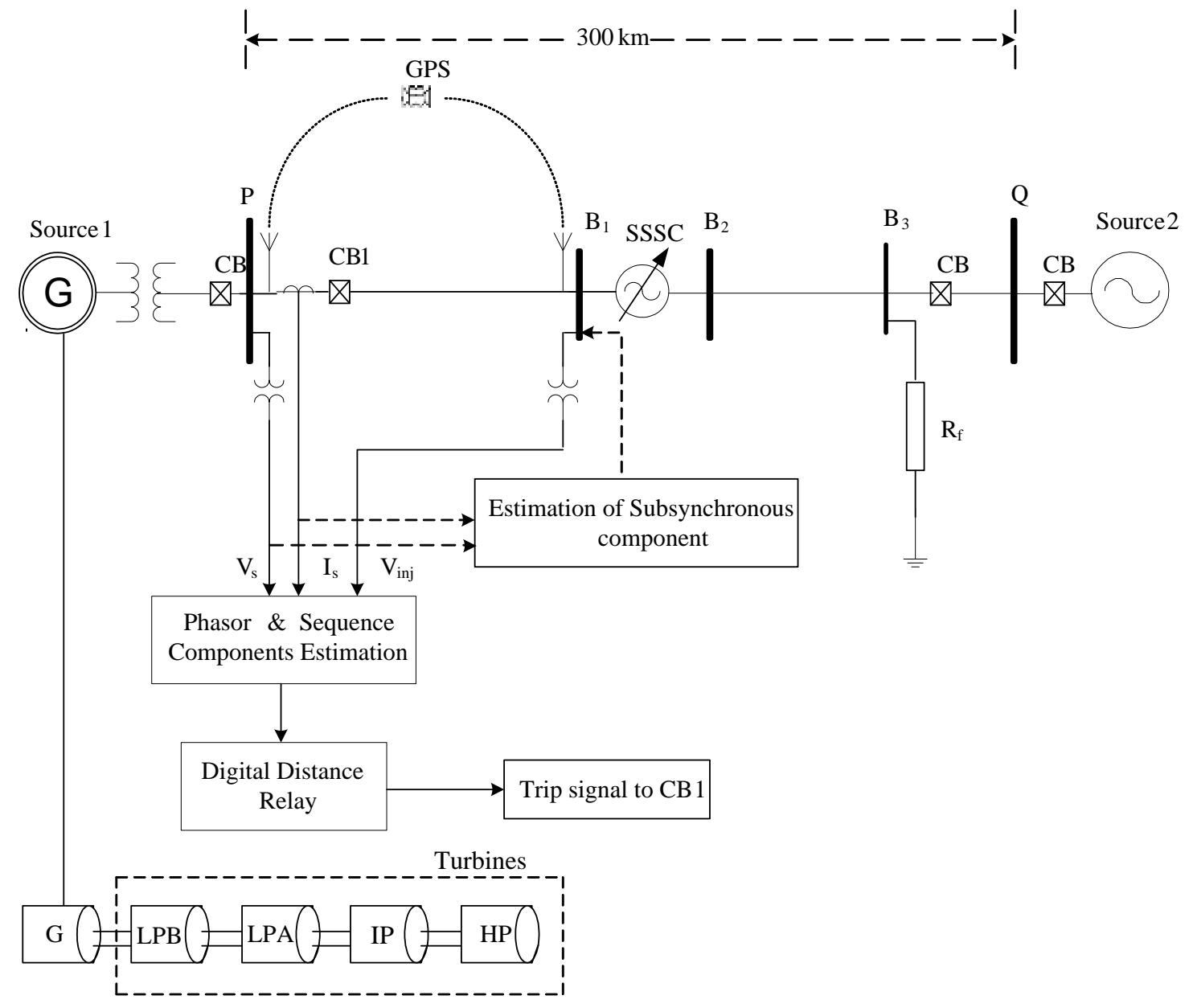

Figure 1.One-line diagram of study system including SSSC [24]

With the injection of series voltage by SSSC into the line, capacitive reactance offered by capacitor bank is nullified and also shifts the system electrical resonance, thus avoids the problem of SSR. The analytical procedure of extracting the components (voltage and current) of subsynchronous frequency from the measured signals explained as follows. 


\section{SUB-SYNCHRONOUS COMPONENT CONTROLLER}

When the rotor of generator oscillates around its rated speed, the terminal voltage in synchronous $d q$ rotating reference frame is given by

$$
\mathrm{v}_{\mathrm{s}}^{\mathrm{dq}}(\mathrm{t})=\mathrm{v}_{\mathrm{s}, \mathrm{f}}^{\mathrm{dq}}(\mathrm{t})+\mathrm{v}_{\mathrm{s}, \mathrm{sub}}{ }^{(\mathrm{dq})}(\mathrm{t})+\mathrm{v}_{\mathrm{s}, \mathrm{sup}}{ }^{(\mathrm{dq})}(\mathrm{t})
$$

The subscripts "f", "sup" and "sub" denote the fundamental, super-synchronous and subsynchronous frequency components of grid voltage. For frequencies above the fundamental, the network offers a little positive damping, and hence the component of this frequency is not considered in the proposed work. If the rotor of generator oscillates with angular frequency $\omega_{\mathrm{m}}$ the base frequency is denoted by $\omega_{0}$. The $\mathrm{dq}_{\mathrm{m}}$ represents another set of coordinate systems which synchronously rotates with synchronous voltage vector, equation (1) can be written as

$$
v_{s}^{d q}(t)=v_{s, f} d q(t)+v_{s, s u b}\left(d q_{m}\right)(t) e^{-j \omega_{m} t}
$$

The rearrangement of equation (2) results the extraction of sub-synchronous component of voltage, so that $\mathrm{v}_{\mathrm{S}, \mathrm{f}}^{\mathrm{dq}}$ and $\mathrm{v}_{\mathrm{s}, \mathrm{sub}}\left(\mathrm{dq}_{\mathrm{m}}\right)$ components are decoupled and then a low-pass filter is applying on the resulting expression [2], the assessment of subsynchronous component (ESSC) controller is expressed as

$$
\begin{gathered}
v_{s, f}{ }^{d q}(t)=H_{f}(p)\left[v_{s}^{d q}(t)-v_{s, s u b}\left(d q_{m}\right)(t) e^{-j\left(\omega_{m} t\right)}\right] \\
i_{, f}^{d q}(t)=H_{f}(p)\left[i^{d q}(t)-i_{s u b}\left(d q_{m}\right)(t) e^{-j\left(\omega_{m} t\right)}\right] \\
v_{s, s u b}{ }^{d q_{m}}(t)=H_{s u b}(p)\left[v_{s}^{d q}(t) e^{j\left(\omega_{m} t\right)}-v_{s, f}^{d q}(t) e^{j\left(\omega_{m} t\right)}\right] \\
i_{s u b} d_{m}(t)=H_{s u b}(p)\left[i^{d q}(t) e^{j\left(\omega_{m} t\right)}-i_{f}^{d q}(t) e^{j\left(\omega_{m} t\right)}\right]
\end{gathered}
$$

Where $\mathrm{H}_{\text {sub }}(\mathrm{p})$ and $\mathrm{H}_{\mathrm{f}}(\mathrm{p})$ represents the low pass filter (LPF) transfer function for subsynchronous and fundamental component, respectively. By writing the equation (3) in synchronous dq-frame as

$$
v_{s, s u b} d q(t)=H_{\text {sub }}\left(p+j \omega_{m}\right)\left[v_{s}^{d q}(t)-v_{s, f}^{d q}(t)\right]
$$

In same way the current can be written as

$$
i_{s, s u b} d q(t)=H_{s u b}\left(p+j \omega_{m}\right)\left[i_{s}^{d q}(t)-i_{s, f}^{d q}(t)\right]
$$

By solving equation (3) and (7), we can obtain the subsynchronous and the fundamental components from the measured voltage. Similarly, by solving equations (4) and (8) we can obtain the subsynchronous and the fundamental components from the measured current. 
To assure the subsynchronous current component to be zero, the subsynchronous voltage component of bus is injected by SSSC in the proposed control strategy. The Laplace domain of SSCC (sub-synchronous component controller) can be written as

$$
\begin{aligned}
& \mathrm{V}_{\mathrm{SSSC}_{\mathrm{sub}}}^{\left(\mathrm{dq}_{\mathrm{m}}\right) *}(\mathrm{~s})=\mathrm{v}_{\mathrm{s}, \mathrm{sub}}^{\mathrm{dq}}(\mathrm{s})+\left(\mathrm{R}+\mathrm{j}\left(\omega_{0}-\omega_{\mathrm{m}}\right)\left(\mathrm{L}_{\mathrm{T}}+\mathrm{L}^{\prime \prime}\right)\right) \mathrm{i}_{\mathrm{sub}}^{\left(\mathrm{dq}_{\mathrm{m}}\right)}(\mathrm{s})+\left(\mathrm{K}_{\mathrm{p}}+\frac{\mathrm{K}_{\mathrm{i}}}{\mathrm{s}}\right)\left[\mathrm{i}_{\mathrm{sub}}^{(\mathrm{dq})}(\mathrm{s})-\right. \\
& \left.\mathrm{i}_{\text {sub }}^{\left(\mathrm{dq}_{\mathrm{m}}\right) *}(\mathrm{~s})\right](9)
\end{aligned}
$$

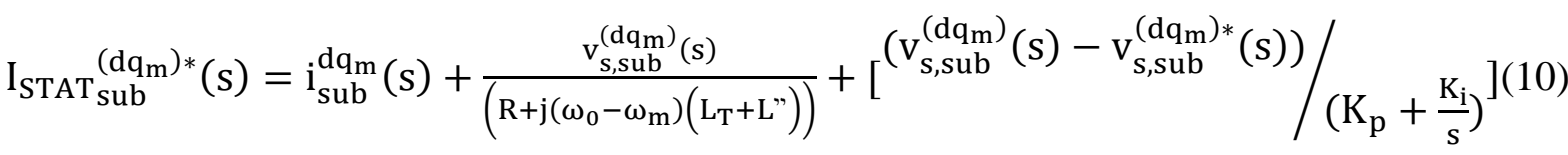

where $\mathrm{R}$ is the resistance, $\mathrm{L}_{\mathrm{T}}$ is the leakage inductance and $\mathrm{L}$ " is thesubtransient inductance of system, transformer and generator. The current and voltage reference are $i_{s u b}^{\left(\mathrm{dq}_{\mathrm{m}}\right) *}, \mathrm{v}_{\mathrm{s}, \mathrm{sub}}^{(\mathrm{dqm}) *}$ while $\mathrm{K}_{\mathrm{p}}$ and $\mathrm{K}_{i}$ is the is the proportional and integral gain of the PI-controller.

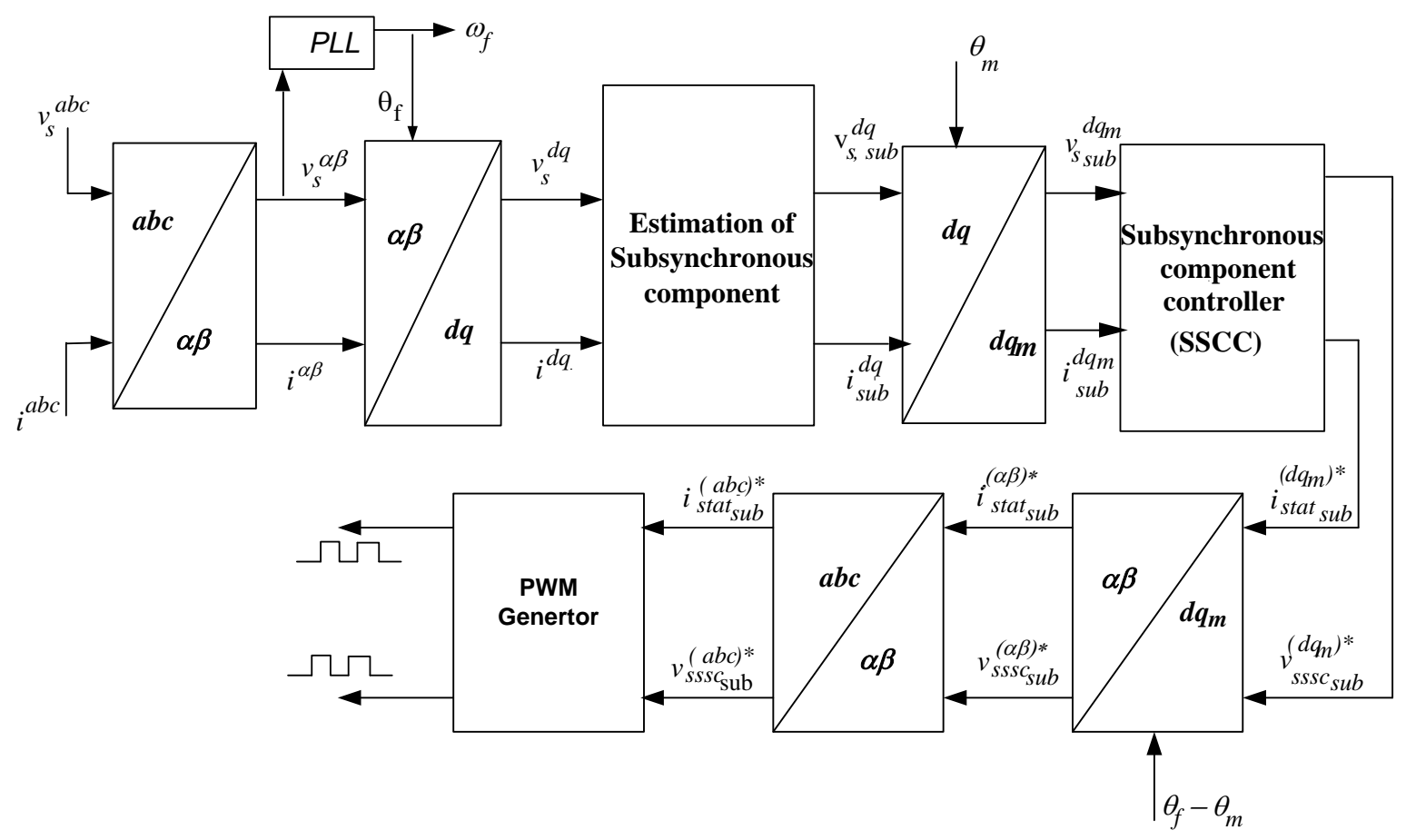

Figure 2. Complete block diagram of subsynchronous component controller

Figure2 illustrates the block diagram of the subsynchronous component controller. First the three-phase voltages and currents which are measured from the line are converted in to $\alpha \beta$ plane and then to dq-cordinate system with the help of $\theta_{\mathrm{f}}$ (angle of transformation) obtained from PLL (phase locked loop). The resultant of the estimation block is the subsynchronous and the fundamental component of current and voltage which are in the dq-frame of reference. The component of subsynchronous quantity is further transformed in to subsynchronousdq $q_{m}$-frame of systems using $\theta_{m}$ (transform angle), obtained by integrating oscillating frequency $\omega_{\mathrm{m}}$. The resultant quantities are then sent to the SSCC (subsynchronous 
component controller). The output quantities of SSCC are again transformed into $\alpha \beta$-plane in stationary reference frame and then transformed into abc in natural reference frame and further given to the PWM pulse generator for switching the three phase 48 pulse voltage source converter [29].

\section{APPARENT IMPEDANCE CALCULATION WITH MID-POINT SSSC}

Figure 3 shows the dual fed transmission line in presence of SSSC at middle of the line and is subjected to line to ground (L-G) fault. When this fault occurs on the right hand side of SSSC at a distance $\rho$ from the relay point, the sequence network (both positive and negative are same) of the study system during the fault is shown in Figure3.

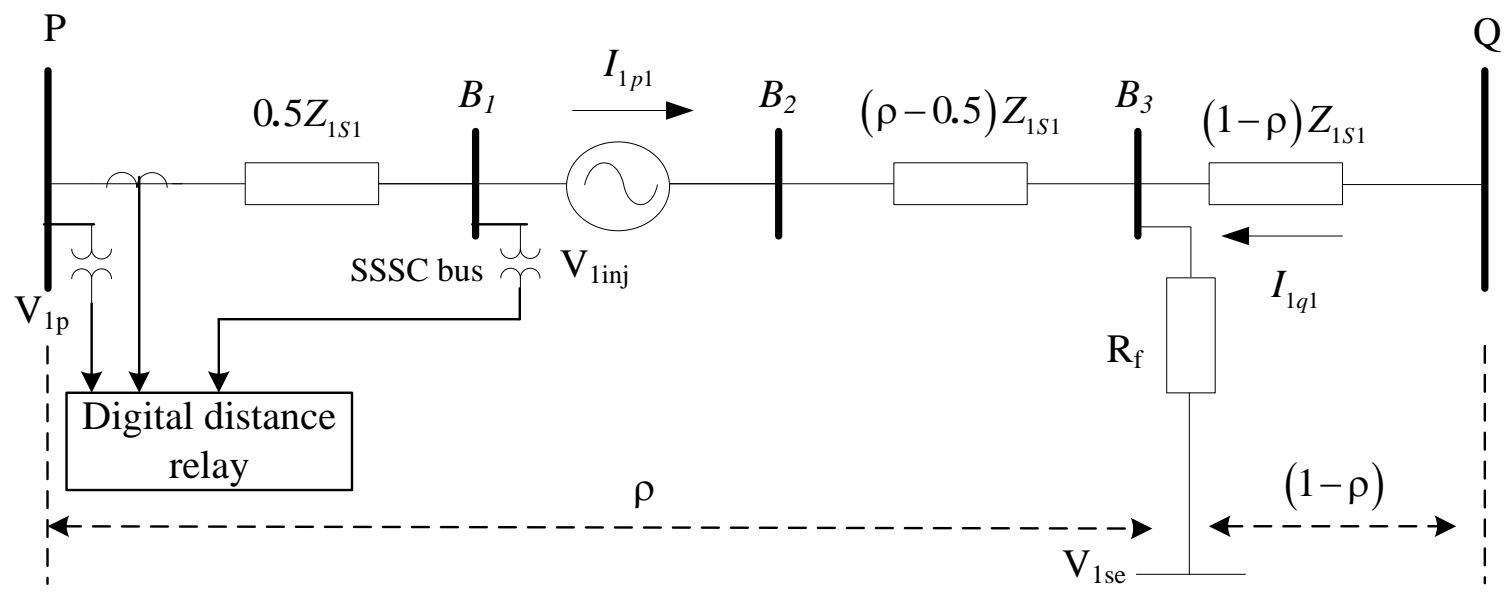

Figure 3. Simplified circuit diagram of study system in presence of SSSC during fault

This section gives the procedure for deriving the apparent impedance expression with SSSC at middle of transmission line. For making the distance relay setting to adaptive and accurate, place the distance relay (digital) at bus $\mathrm{P}$ uses the samples of current and voltage obtained with the help of instrument transformers. The apparent impedance is calculated with the use of symmetrical components of current and voltage. The pre-process of current and voltage samples are required to compute phasors of fundamental with FFT), has the capability to filter the decaying components of dc, inter-harmonic components and harmonics of other present in the signal [26-28].

By applying Kirchhoff's law to the Figure 3, the sequence voltage at the relay location P, for L-G fault after SSSC can be written as

$$
V_{1 p}=\rho Z_{1 s 1} I_{1 p 1}+V_{1 i n j}+\frac{R_{f}}{(1-\rho)}\left(I_{1 p 1}-Z_{1 s 1}+\frac{V_{1 i n j}}{Z_{1 s 1}}\right)
$$

For negative sequence and zero sequence voltages are derived in the similar way; 


$$
\begin{gathered}
V_{2 p}=\rho Z_{1 s 1} I_{2 p 1}+V_{2 i n j}+\frac{R_{f}}{(1-\rho)}\left(I_{2 p 1}-Z_{2 s 1}+\frac{V_{2 i n j}}{Z_{1 s 1}}\right) \\
V_{0 p}=\rho\left(Z_{0 s 1} I_{0 p 1}\right)+V_{0 i n j}+\frac{R_{f}}{(1-\rho)}\left(I_{0 p 1}-Z_{0 s 1}+\frac{V_{0 i n j}}{(1-\rho)\left(Z_{0 s 1}-Z_{0 m}\right)}\right)
\end{gathered}
$$

The derivation of voltage at the relay bus is written as:

$$
\mathrm{V}_{\mathrm{p}}=\rho \mathrm{Z}_{1 \mathrm{~s} 1} \mathrm{I}_{1 \mathrm{p} 1}+\rho\left(\mathrm{Z}_{0 \mathrm{~s} 1}-\mathrm{Z}_{1 \mathrm{~s} 1}\right) \mathrm{I}_{0 \mathrm{p} 1}+\mathrm{V}_{\mathrm{inj}}+\frac{\mathrm{R}_{\mathrm{f}}}{(1-\rho)}\left(\mathrm{I}_{\mathrm{p} 1}-\mathrm{Z}_{1 \mathrm{~s} 1}+\frac{\mathrm{V}_{\text {inj }}}{\mathrm{Z}_{1 \mathrm{~s} 1}}+\mathrm{V}_{0 \mathrm{inj}}\left(\frac{1}{\mathrm{Z}_{1 \mathrm{~s} 1}}\right)\right)
$$

where:

$$
\begin{gathered}
V_{0 p}+V_{1 p}+V_{2 p}=V_{p} \\
I_{0 p 1}+I_{1 p 1}+I_{2 p 1}=I_{p 1} \\
V_{0 i n j}+V_{1 i n j}+V_{2 i n j}=V_{\text {inj }}
\end{gathered}
$$

Where, $\mathrm{V}_{\mathrm{P}}, \mathrm{I}_{\mathrm{P} 1}$ are the phase voltage and current at relay location at bus $\mathrm{P}$ respectively, $\mathrm{V}_{0 \mathrm{P}}, \mathrm{V}_{1 \mathrm{P}}, \mathrm{V}_{2 \mathrm{P}}$ and $\mathrm{I}_{0 \mathrm{P} 1}, \mathrm{I}_{1 \mathrm{P} 1}, \mathrm{I}_{2 \mathrm{P} 1}$ are sequence phase voltages and current respectively. $\mathrm{I}_{0 \mathrm{q} 1}, \mathrm{I}_{1 \mathrm{q} 1}, \mathrm{I}_{2 \mathrm{q} 1}$ are sequence phase currents at bus $\mathrm{Q}$.

$\mathrm{V}_{0 \text { se }}, \mathrm{V}_{1 \mathrm{se}}, \mathrm{V}_{2 \text { se }}$ are sequence phase voltages at fault location $\mathrm{E} ; \mathrm{R}_{\mathrm{f}}$ is the fault resistance. $\mathrm{Z}_{0 \mathrm{~s} 1}, \mathrm{Z}_{1 \mathrm{~s} 1}, \mathrm{Z}_{2 \mathrm{~s} 1}$ are sequence impedances of the transmission line and $\mathrm{Z}_{1 \mathrm{~s} 1}=\mathrm{Z}_{2 \mathrm{~s} 1}$.

$\mathrm{Z}_{0} \mathrm{~S}_{1}, \mathrm{Z}_{1} \mathrm{~S}_{1}, \mathrm{Z}_{2} \mathrm{~S}_{1}, \mathrm{Z}_{0} \mathrm{~S}_{2}, \mathrm{Z}_{1} \mathrm{~S}_{2}, \mathrm{Z}_{2} \mathrm{~S}_{2}$ are sequence impedance of source 1 and source 2 respectively. $\rho$ is fault per unit distance from relay location.

The apparent impedance of distance relay without SSSC, for SLG fault, can be computed by using bellow equation:

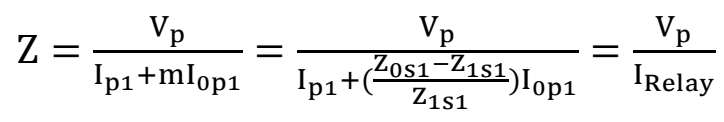

where, $m$ is compensation factor and is given by $m=\frac{z_{0 s 1}-z_{1 s 1}}{z_{1 s 1}}$

The seen apparent impedance of conventional distance relay with SSSC is written as

$$
\mathrm{Z}_{\mathrm{app}}=\rho \mathrm{Z}_{1 \mathrm{~s} 1}+\frac{\mathrm{R}_{\mathrm{f}}}{(1-\rho) \mathrm{I}_{\text {Relay }}}\left(\mathrm{I}_{\mathrm{p} 1}-\mathrm{Z}_{1 \mathrm{~s} 1}\right)+\Delta \mathrm{Z}
$$

When there is no SSSC, $\Delta Z$ in (20) is zero and the apparent impedance is to be same as uncompensated lines, so $\Delta Z$ depends on the SSSC and equals;

$$
\Delta \mathrm{Z}=\frac{\mathrm{V}_{\text {inj }}}{\mathrm{I}_{\text {Relay }}}+\frac{\mathrm{R}_{\mathrm{f}}}{(1-\rho) \mathrm{I}_{\text {Relay }}}\left(\frac{\mathrm{V}_{\text {inj }}}{\mathrm{Z}_{1 \mathrm{~s} 1}}+\mathrm{V}_{\text {0inj }}\left(\frac{1}{\mathrm{Z}_{1 \mathrm{~s} 1}}\right)\right)
$$

It is clear in equation (18) that, the existence of SSSC in fault loop affects the computed impedance by relay, with a fault distance of 0.5 p.u from relay or in the absence of SSSC, the effect of it in impedance $\mathrm{Z}=\mathrm{Z}_{\mathrm{app}}$ is only by $\mathrm{R}_{\mathrm{f}}$. 
For a line to line (L-L) fault, the calculation of distance relay apparent impedance can be given by:

$$
\begin{aligned}
& \mathrm{V}_{1 \mathrm{se}}=\alpha \mathrm{V}_{2 \mathrm{se}} \\
& \text { Where: } \alpha=-0.5+\mathrm{j} 0.886
\end{aligned}
$$

From equation (13), (14) and (23) we have obtained final equation of line to line fault with mid-point SSSC given by

$$
\begin{aligned}
& Z_{\text {app }}=\rho Z_{1 s 1}+\frac{R_{f}}{(1-\rho) I_{\text {Relay }}}\left(I_{p 1}-\alpha I_{2 p 1}-k_{1}\right)+\Delta Z \\
& \Delta Z=\frac{V_{\text {inj }}-\alpha V_{2 \text { inj }}}{I_{\text {Relay }}}+\frac{R_{f}}{(1-\rho) I_{\text {Relay }}}\left(\frac{\left(\mathrm{V}_{1 \text { inj }}-\alpha V_{\text {2inj }}\right)}{Z_{1 s 1}}\right)
\end{aligned}
$$

In above equation $R_{\mathrm{f}}$ is the fault resistance between two phases. According to equation (21) for $\mathrm{R}_{\mathrm{f}}=0, \mathrm{SSSC}$ is due to the positive and negative sequence voltage differences.

\section{ADAPTIVE DISTANCE PROTECTION SCHEME WITH SSSC}

The prime objective of the proposed research work is to design an adaptive algorithm for distance protection in presence of SSSC to mitigate SSR at mid-point of transmission line. The research objective is achieved by making necessary modifications in the calculation of apparent impedance formula, which is in equation (17). Equation (17) compares with relay setting $\left(\mathrm{Z}_{\mathrm{set}}\right)$ of first zone to take the exact decision of no trip or trip during fault in the protected zone. The expression for a new distance relay setting is obtained with the data of series injected voltage $\left(\mathrm{V}_{\mathrm{inj}}\right)$ at relaying bus $\mathrm{P}$. Therefore, equate the calculated apparent impedance give in equation (17) to distance relay setting of which is $80 \%$ of line to be protected.

$$
\mathrm{Z}_{\mathrm{app}}=\mathrm{Z}_{\text {set }}=0.8 \mathrm{Z}_{\mathrm{line} 1}=0.8 \mathrm{Z}_{1 \mathrm{~s} 1}
$$

Comparing equation (20) and (26), we get

$$
0.8 \mathrm{Z}_{1 \mathrm{~s} 1}=\rho \mathrm{Z}_{1 \mathrm{~s} 1}+\frac{\mathrm{R}_{\mathrm{f}}}{(1-\rho) \mathrm{I}_{\text {Relay }}}\left(\mathrm{I}_{\mathrm{p} 1}-\mathrm{Z}_{1 \mathrm{~s} 1}\right)+\Delta \mathrm{Z}
$$

Considering $\mathrm{R}_{\mathrm{f}}=0$, the right half term of equation (24) can be eliminated by making changes equation (25) and is expressed as

$$
0.8 Z_{1 \mathrm{~s} 1}=\rho Z_{1 \mathrm{~s} 1}+\frac{\mathrm{V}_{\text {inj }}}{\mathrm{I}_{\text {Relay }}}
$$

per unit distance $(\rho)$ can be rewritten as in equation

$$
\rho_{1}=0.8 \mathrm{Z}_{1 \mathrm{~S} 1}-\left(\frac{\mathrm{V}_{\mathrm{inj}}}{\mathrm{I}_{\text {Relay }} \mathrm{Z}_{1 \mathrm{~s} 1}}\right)
$$


where, $\rho$ is becomes $\rho_{1}$ and noted as adaptive setting factor. After checking the calculated apparent impedance $\left(\mathrm{Z}_{\mathrm{app}}\right)$ in existence of SSSC at middle of the line, then only the adaptive distance protection setting scheme will take the decision of trip. Therefore to obtain the new setting, equation (26) is multiplied with $Z_{\text {line } 1}$.

$$
\mathrm{Z}_{\text {setnew }}=\rho \mathrm{Z}_{1 \mathrm{~s} 1}=\rho_{1} \mathrm{Z}_{\text {Line1 }}
$$

Multiplying equation (26) with $\left(\mathrm{Z}_{\text {line1 }}\right)$ and substituting in (27), we get

$$
\mathrm{Z}_{\text {setnew }}=\left[0.8 \mathrm{Z}_{1 \mathrm{~S} 1}-\left(\frac{\mathrm{V}_{\text {inj }}}{\mathrm{I}_{\text {Relay }} \mathrm{Z}_{1 \mathrm{~s} 1}}\right)\right] \mathrm{Z}_{\text {line } 1}
$$

From equation (28), the fallowing points are addressed

(i) If SSSC injects capacitive compensation then adaptive zone is increased while for inductive compensation adaptive zone is decreased.

(ii) Depending on the compensation level the proposed adaptive distance protection setting will automatically adjust the first zone reach.

(iii) With the nature of injected voltage the adaptive distance protection primary zone setting formula adjusted adaptively.

(iv) Injected voltage will affect the calculation of apparent impedance with fault after SSSC.

(v) The location of SSSC also affects the calculation of apparent impedance.

\section{TRANSIENT SIMULATION RESULTS}

To investigate the effectiveness of the suggested adaptive distance protection, the system shown in Fig.1, is simulated using PSCAD/EMTDC software (Manitoba HVDC Research Centre, Winnipeg, Manitoba, Canada) [30]. A Symmetrical (LLL) fault is applied to the grid for $55 \%$ series compensation at $1 \mathrm{sec}$ with $0.05 \mathrm{sec}$ fault clearing time. Even though the fault is cleared, the torque and stress between the LPB and generator is very high due to SSR and are shown in Figure 4.There is an increase in torque and mechanical stress with a fast rate even though the fault is cleared and this completely damages the turbine shaft system. The injected voltage of SSSC in series with the line is decided by the firing angle of PWM generator, and is obtained from the subsynchronous component estimation control. The mitigation of SSR with the help of SSSC is shown in Figure 5 and the injected voltage of SSSC to mitigate SSR is shown in Figure 6. With the proper injection of series voltage into the line, the turbine-generator oscillations stress between LPB and Generator are reduced to a 
low extent that will not harm to the shaft system. Load-flow analysis is used for calculating the magnitudes of generator voltage and load angles. A three level 48-pulse VSC is used for the design SSSC [29].
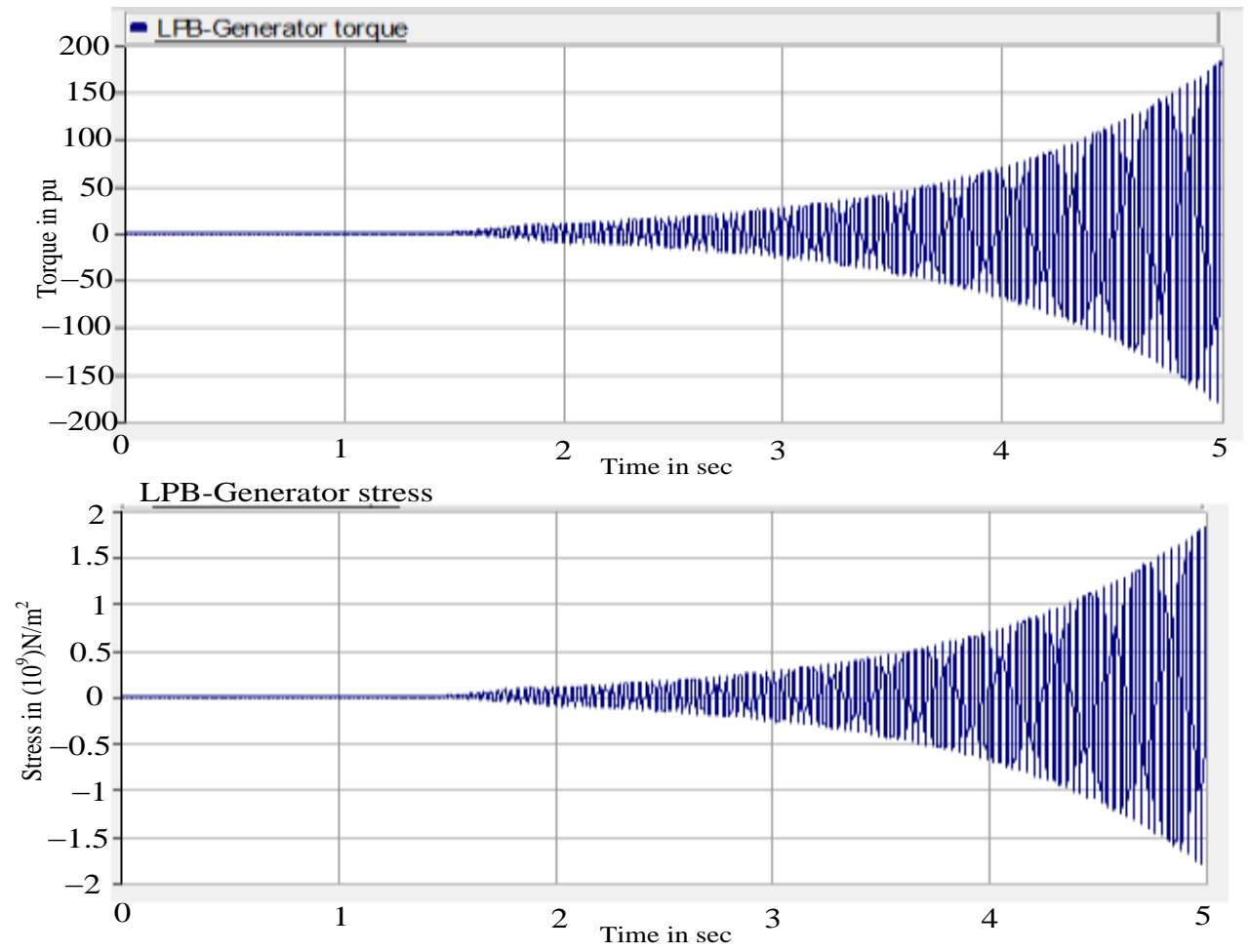

Figure 4. Simulated Turbine-Generator shaft Torque, Stress between LPB-GEN of Study system model without SSC based SSSC. 

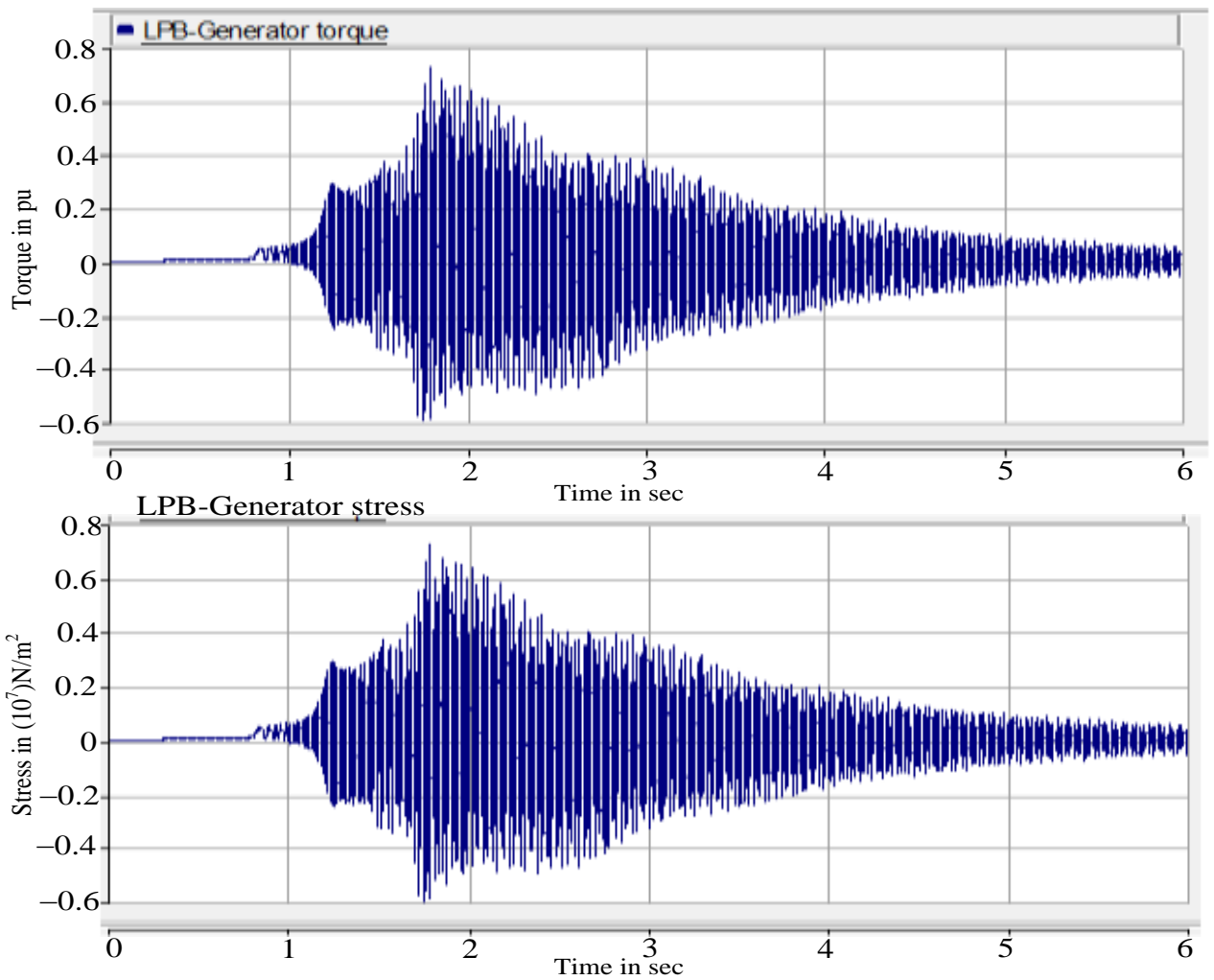

Figure 5. Simulated Turbine-Generator shaft Torque, Stress between LPB-GEN of Study system model with SSC based SSSC.

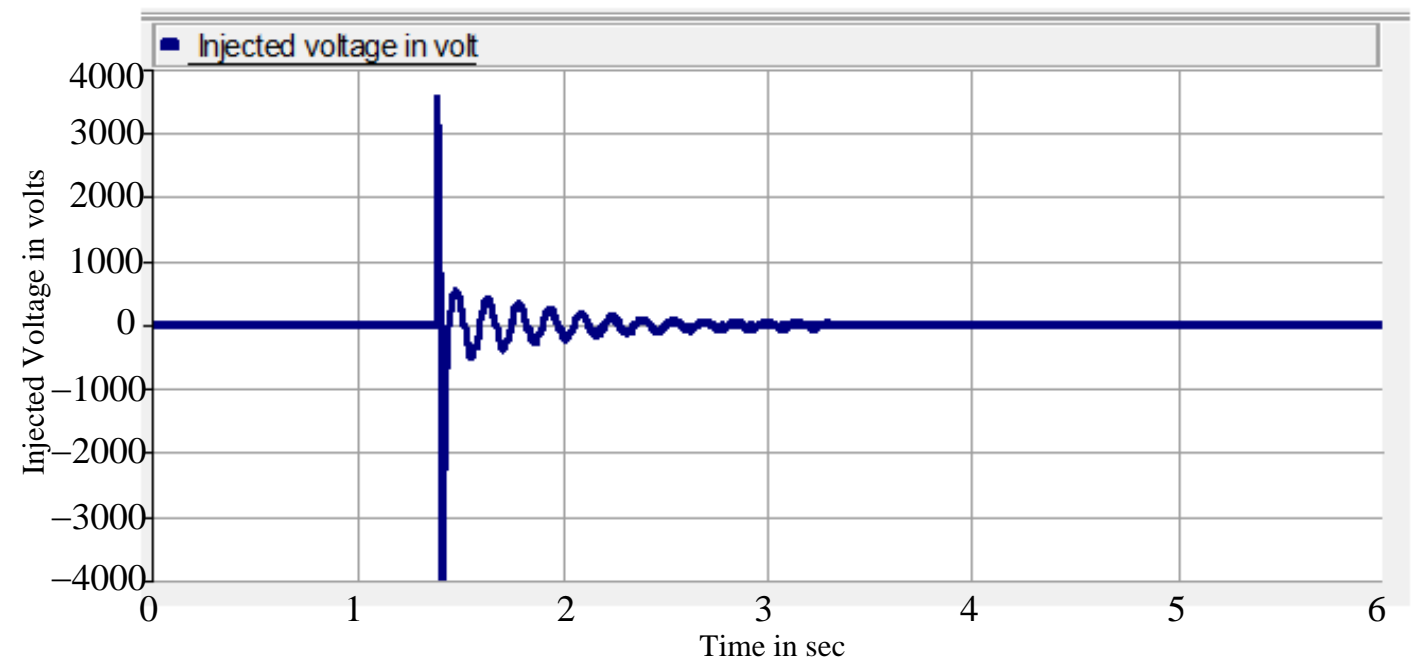

Figure 6. Injected Voltage in to the line to mitigate SSR with SSSC. 


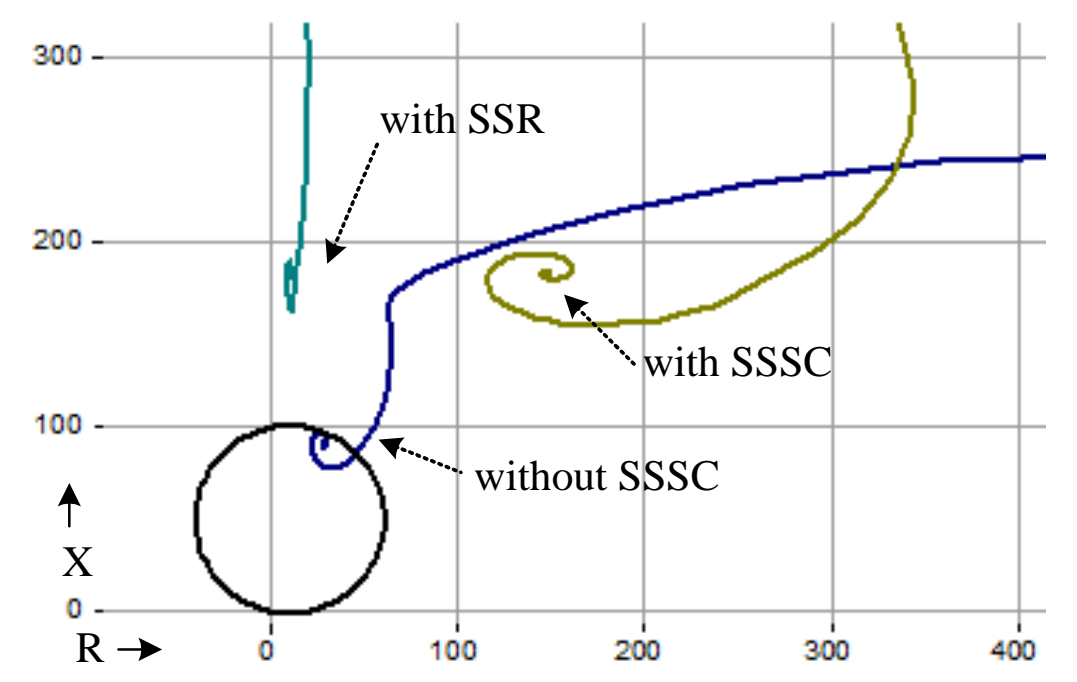

Figure 7. First zone trajectories of distance relay without SSSC, with SSR and with SSSC

First zone trajectories of distance relay under normal operation without SSSC represented by blue line shown in Figure 7. With SSR the operating point is out of the zone (under-reach) shown by the dark green line. The operating point with SSSC also shifts to out of the zone (under-reach) shown by the green line. Figure 7 describes the affect of SSR and existence of SSSC on distance protection.

To estimate the adaptive first zone settings of distance rely, control over the setting value of SSSC i.e. $V_{\text {Ref }}$ is set between \pm 0.1 p.u. The SSSC is connected at mid-point and it comes into the system at $1.05 \mathrm{sec}$. The voltage at mid-point is decreases with the absorption of Inductive reactive power by SSSC as compared to the usual working voltage without SSSC. This results the reduction in relaying bus voltage and further a decrease in seen apparent impedance of distance relay causing over-reach. The simulation result of Adaptive distance relay with SSSC setting value $V_{\text {ref }}=-0.1$ p.u., the setting factor $\rho_{1}$ is illustrated in Figure 8 for power flow in forward from $\mathrm{P}$ to Q. When SSSC is connected at $1.05 \mathrm{sec}$ into the system and absorbs reactive power of inductive, the setting factor $\rho_{1}$ is decreased adaptively and it settles to 0.7671 per unit distance value by taking 13 milliseconds to get a new first zone adaptive setting. This new adaptive setting factor is used to define dynamic mho distance relay reach as shown in Figure9. It is observed that for SSSC setting value $\mathrm{V}_{\text {ref }}=-0.1$ p.u., a reduction in adaptive relay reach which is represented in dark green colour as compared to relay reach of conventional represented by red colour. 


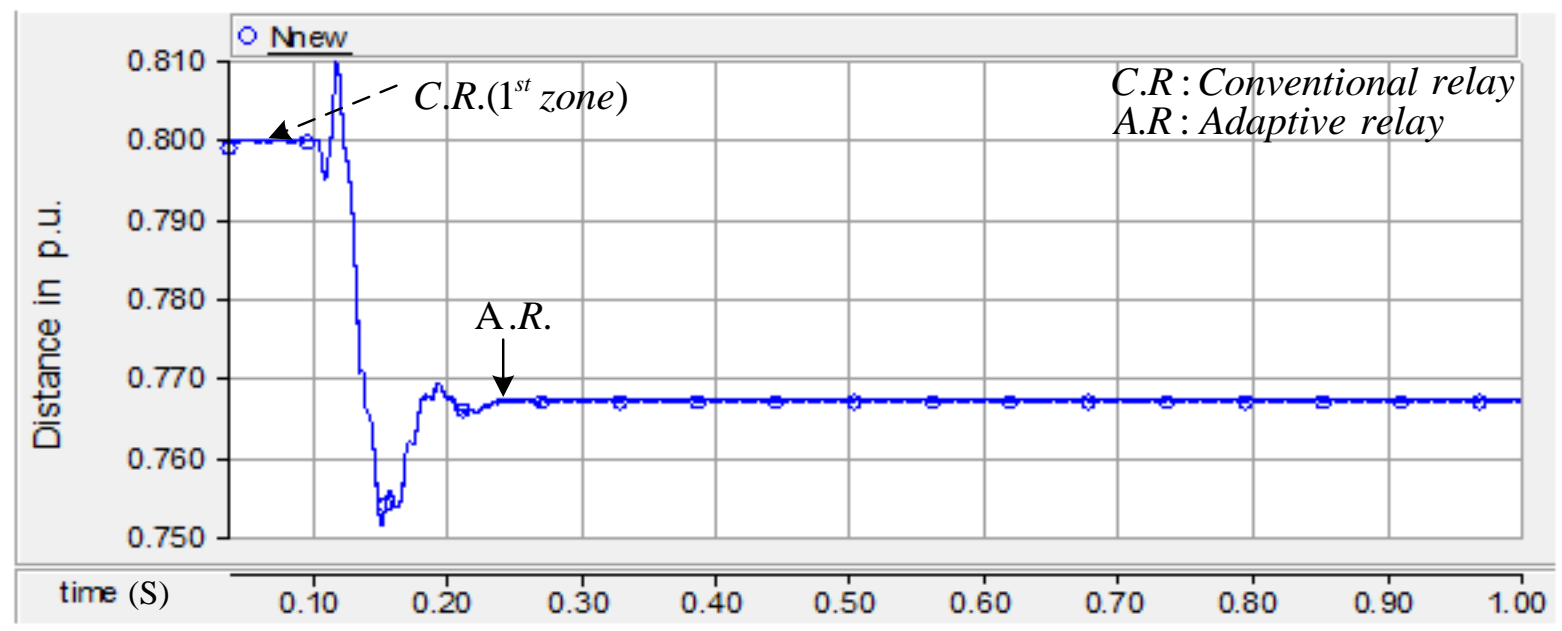

Figure 8. Adaptive distance setting factor $\rho_{1}$ with SSSC setting value $V_{\text {ref }}=-0.1$ p.u., with power flow from $P$ to $\mathrm{Q}$

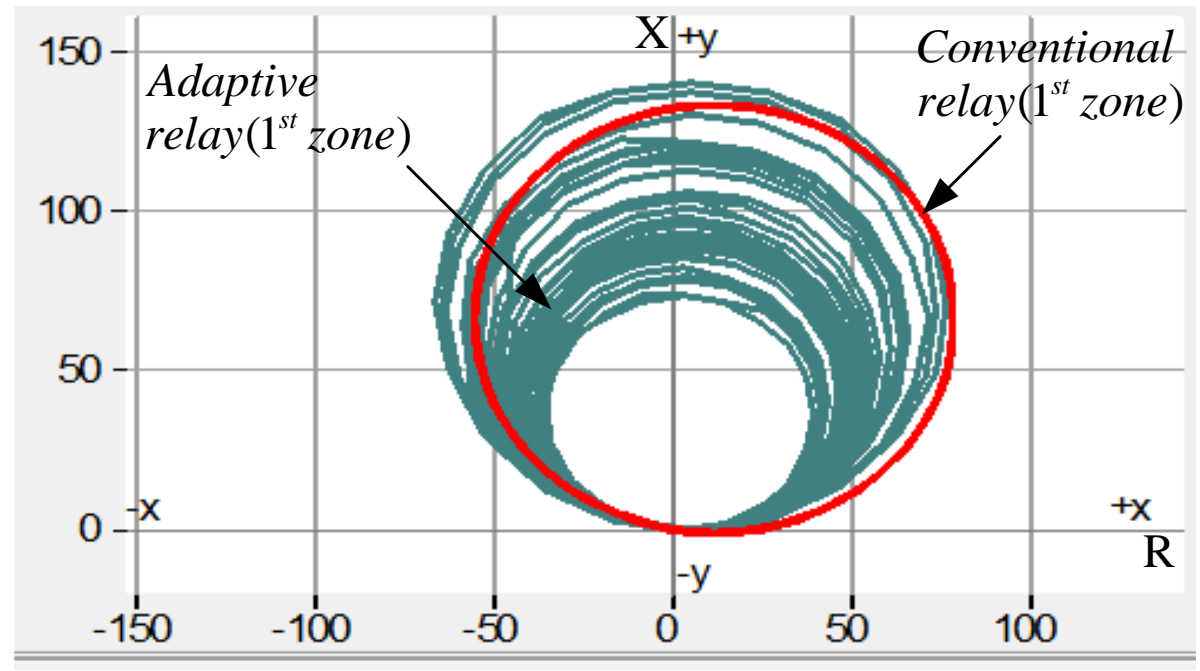

Figure 9. Conventional versus adaptive mho characteristics with SSSC setting value $V_{\text {ref }}=-0.1$ p.u., with power flow from $\mathrm{P}$ to $\mathrm{Q}$

When SSSC setting value is $\mathrm{V}_{\text {ref }}=0.1$ p.u., there is an increase in voltage at mid-point as compared to voltage under usual operating condition without SSSC. Subsequently the relaying voltage of bus and the seen apparent impedance of distance relay also increase and leads to under-reach. The adaptive relay setting factor $\rho_{1}$ obtained for $\operatorname{SSSC} \mathrm{V}_{\text {ref }}=0.1$ p.u. into the system is illustrated by Figure10 for flow of power in forward. The setting factor of relay is 0.8 without SSSC and is adaptively increases to 0.8425 per unit distance value with SSSC by taking 25 milliseconds to settle shown in Figure10. 


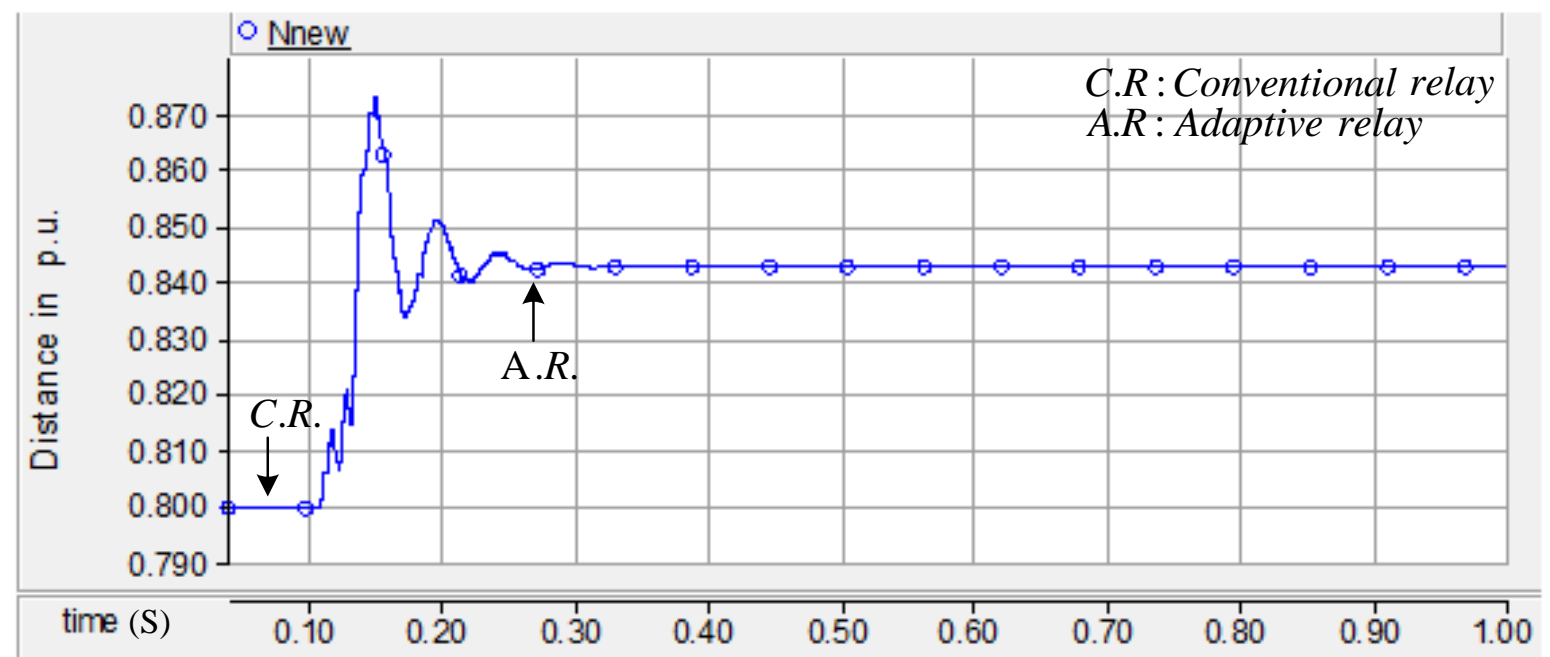

Figure 10. Adaptive distance setting factor $\rho_{1}$ with SSSC setting value $V_{\text {ref }}=0.1$ p.u., with power flow from $P$ to $\mathrm{Q}$

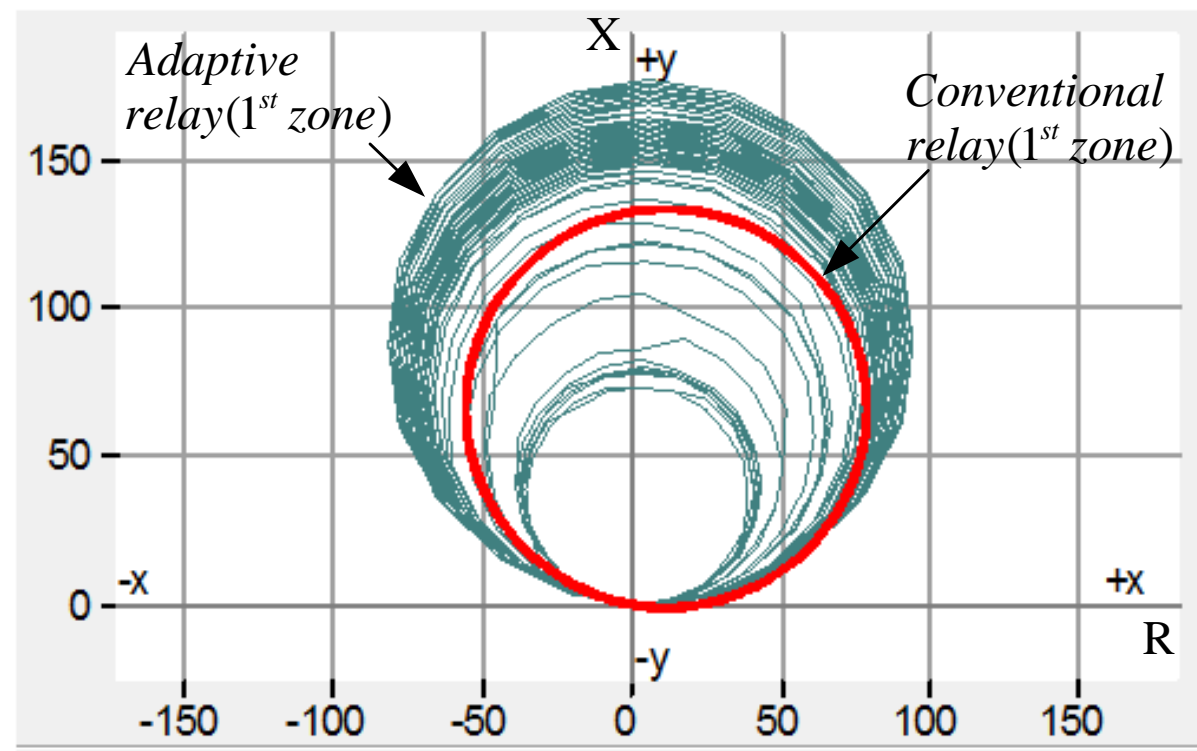

Figure 11. Conventional versus adaptive mho characteristics with SSSC setting value $V_{\text {ref }}=0.1$ p.u., with power flow from $\mathrm{P}$ to $\mathrm{Q}$

Figure11 shows the conventional relay reach represented by red colour and adaptive mho relay reach represented by black colour. It is seen that for SSSC setting value $V_{\text {ref }}=0.1$ p.u., the reach of relay is increased adaptively as compared to conventional relay reach. In the same way, conclusion is drawn from Figures7-10 with the injection of capacitive and inductive reactive power by SSSC to make distance relay setting factor adaptive. The adaptive setting factor prequires a less time to settle (approximately one and half cycle) for $\mathrm{V}_{\text {ref }}=-0.1$ p.u., and around three cycle to get settle for $\mathrm{V}_{\text {ref }}=0.1$ p.u.. It is because of the use 
of PI controller and is having its own settling time constant which is represented in modelling of SSSC in the paper.

Adaptive setting factor for SSSC reference value, $V_{\text {ref }}=-0.1$ p.u. for power flow in forward direction is 0.7671 p.u. distance and is less as compared to SSSC reference value, $V_{\text {ref }}=0.1$ p.u in forward power flow is 0.8425 p.u distance. From Figures 9 and 11, the time taken to reach new adaptive setting is different because it depends on capacitive/inductive compensation mode, settling time of PI controller and interfacing transformer of SSSC.

Figure 12 shows the variation of adaptive setting factor with change in SSSC reference voltage $V_{r e f}$ in the step of $0.01 \mathrm{p}$. u. The capacitive reactive power injection is represented by positive value and the inductive reactive power absorption represented by negative value. When SSSC is in inactive mode the system neither injects nor absorbs any reactive power and the observed setting factor is 0.7956. This is due to the reactance of interfacing transformer which comes into circuit of 0.1 per unit. For flow of power in forward direction from $\mathrm{P}$ to $\mathrm{Q}$, adaptive setting factor for first zone is 0.8425 and 0.7671 per unit distance for $\mathrm{V}_{\text {ref }}=0.1$ p.u., and $\mathrm{V}_{\text {ref }}=-0.1$ p.u., respectively as shown in Figure 12 .

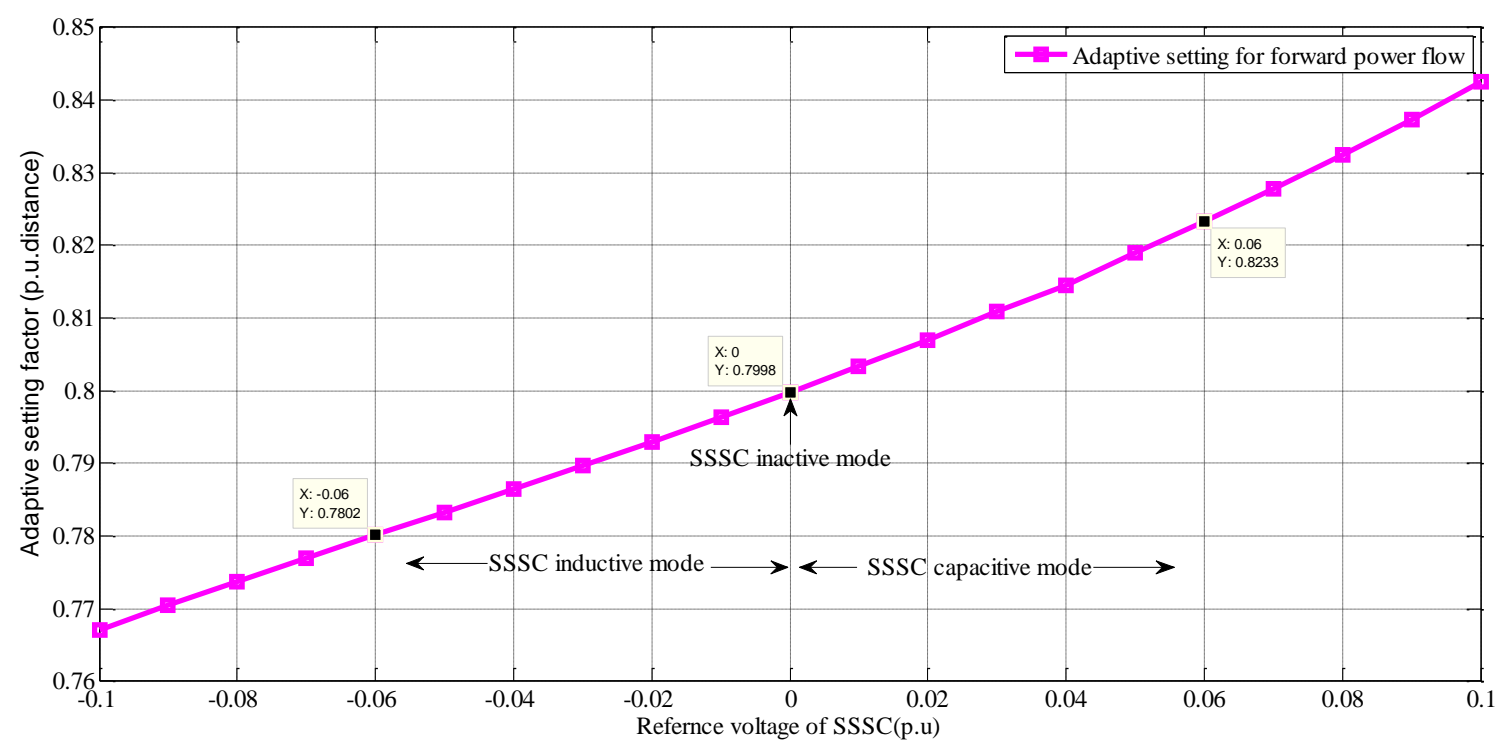

Figure 12. Adaptive distance relay setting factor Vs Reference Voltage of SSSC setting value 


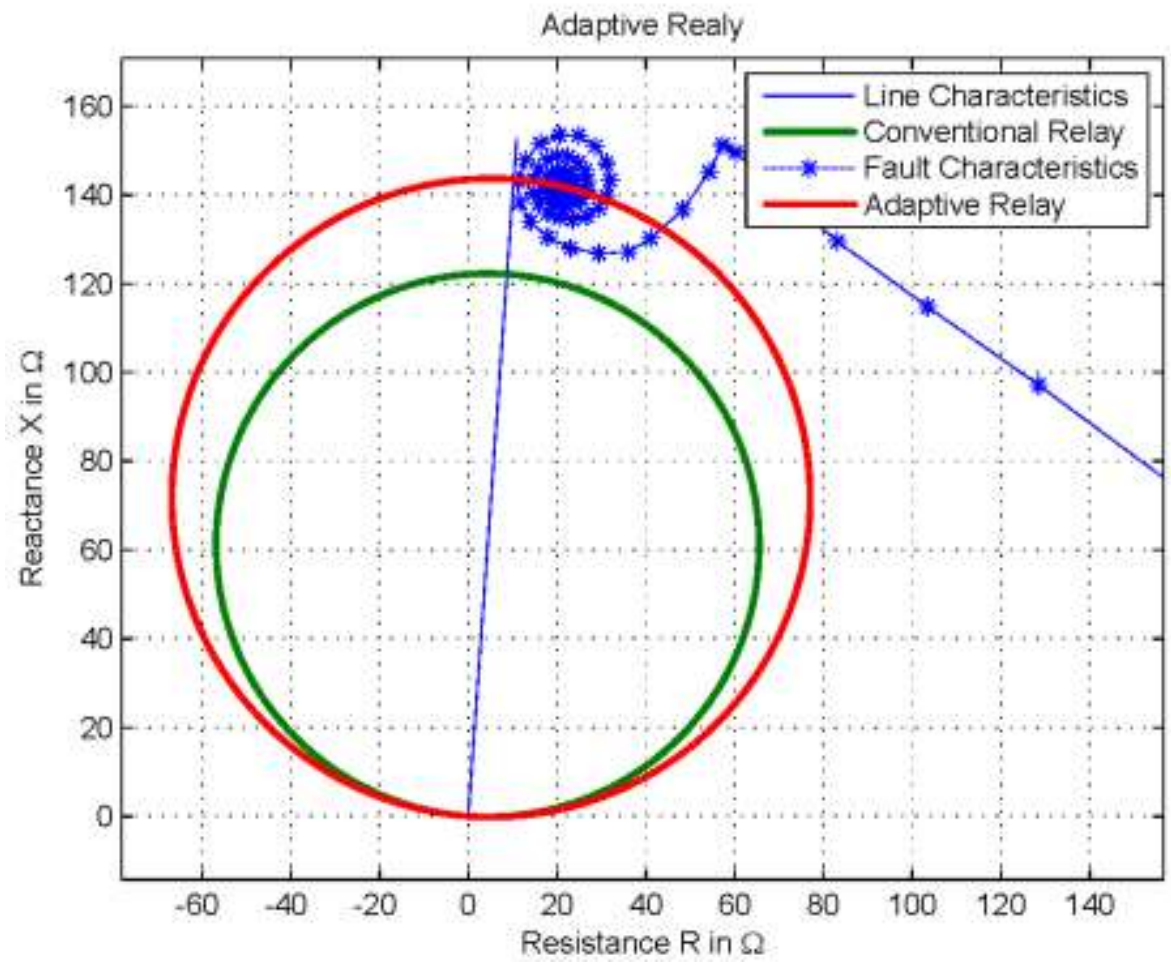

Figure 13. Ag fault at $80 \%$ of line length with $\operatorname{SSSC}(0.1)$ and $1 \Omega$ fault resistance

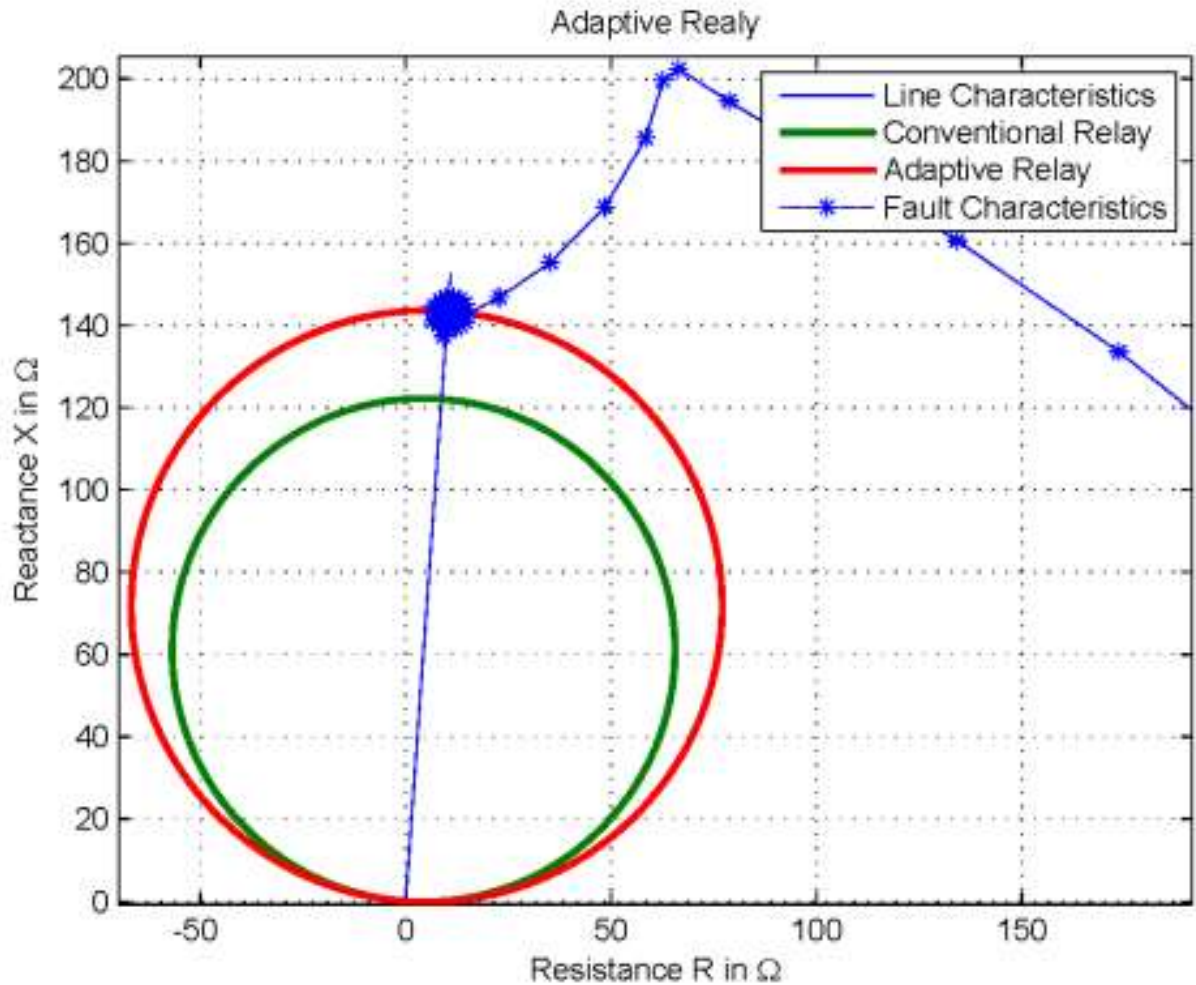

Figure 14. BCg fault at $80 \%$ of line length with $\operatorname{SSSC}(0.1)$ and zero fault resistance 


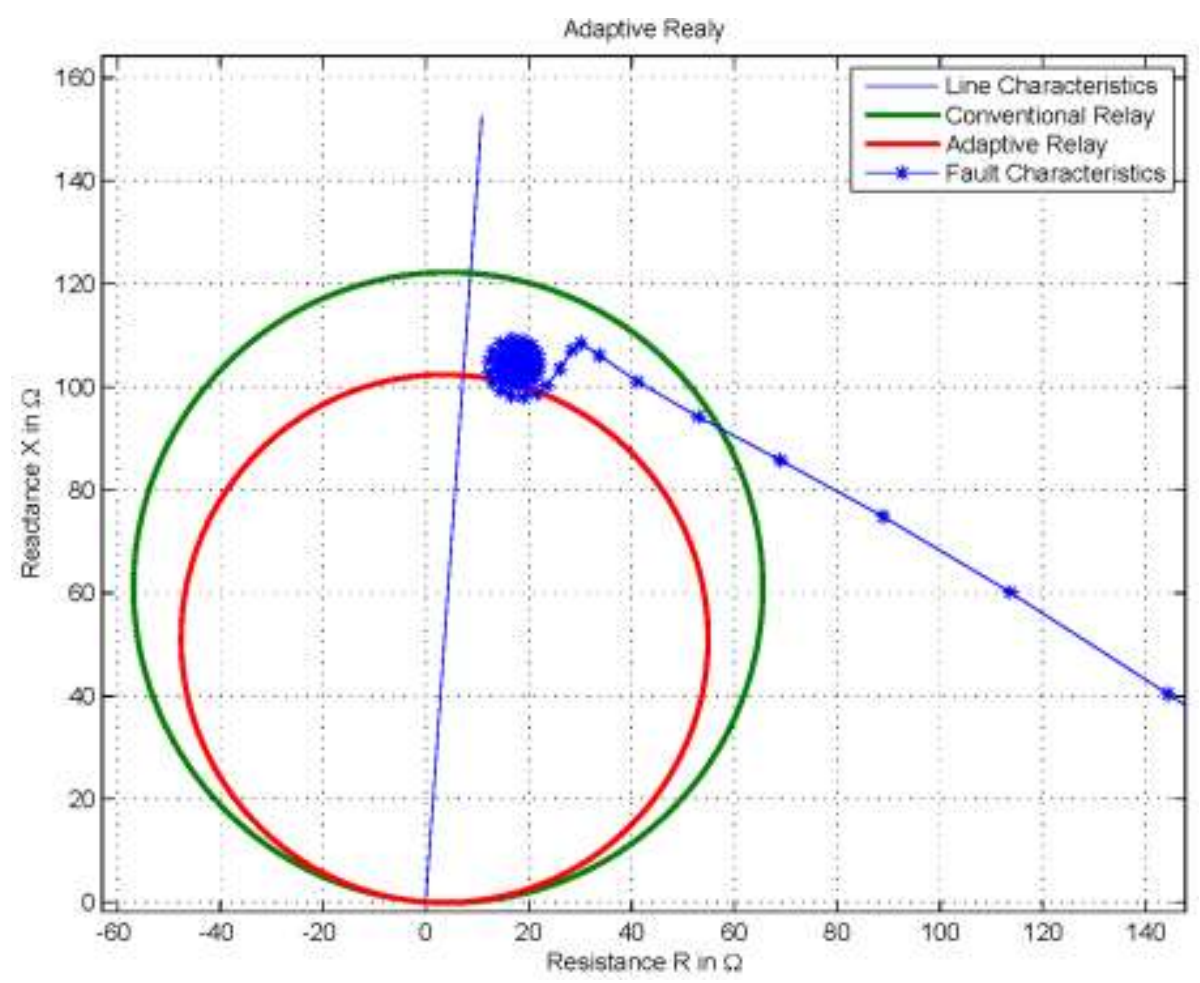

Figure 15. Ag fault at $85 \%$ of line length with $\operatorname{SSSC}(-0.1)$ and $1 \Omega$ fault resistance

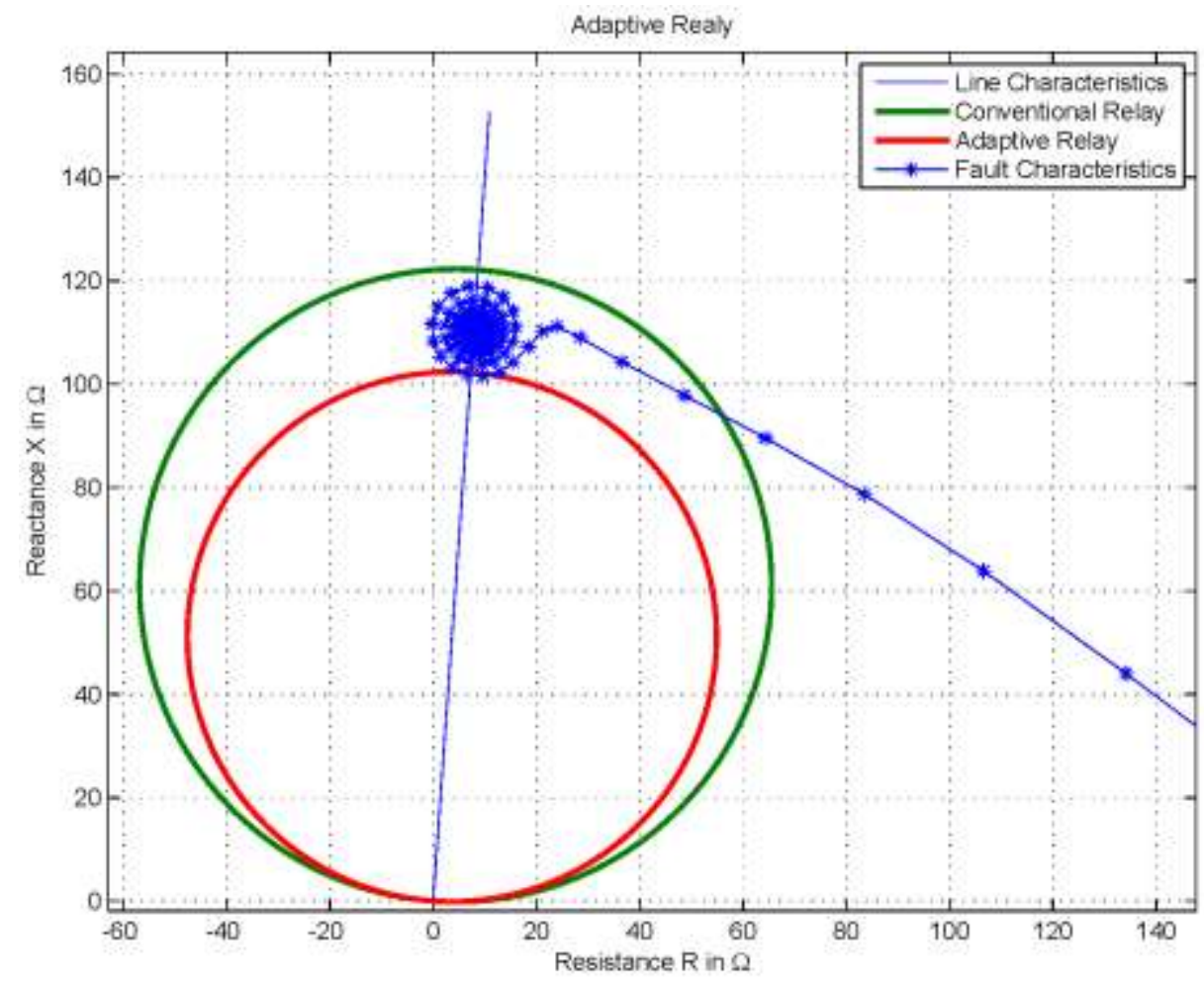

Figure 16. AB fault at $90 \%$ of line length with SSSC (-0.1) and Zero fault resistance

For different changing compensation mode and level, the adaptive relay settings have been calculated and stored in the relay lookup table. So, when the adaptive relay have the feedback from the compensation $\left(\mathrm{V}_{\mathrm{ijn}}\right)$ the pre-calculated setting will used to detect and locate the fault point which make the relay adaptive. Theses settings stored in the lookup table is for 
proposed system and for any other system, using the adaptive relay equation and other related parameters, the settings can be calculated to load into the relay lookup module. The adaptive relay response for the associated problem of underreach and overreach of conventional distance relay have been shown with the different fault conditions in the figure 13-16. Its highly important to check for the boundary conditions, like when fault is occurring near to the first zone of protection for underreach settings and ahead from first zone setting for overreach setting in different compensation mode.

Figure 13 shows the results for Ag fault at $80 \%$ of line length with positive SSSC compensation (0.1) with $1 \mathrm{ohm}$ fault resistance. The appropriate legends are shown in the figure for better understanding. It is observed that, the conventional relay underreach the fault trajectory and adaptive relay able to locate the fault in its first of protection. In simulation and numerical modelling of relay, it is assumed that, if 10 continues samples lies in the zone of protection than only relay will issue the trip decision, else no trip for both the relays. Similar observations are made in Figure 14 for BGg fault at $80 \%$ of line length and results are highly satisfactory.

Figure 14 shows the results for SSSC compensation (-0.1) for Ag fault at $85 \%$ of line length with zero resistance. The in this mode of SSSC compensation conventional relay detects the fault in its first zone and hence overreach the fault point. Whereas, adaptive relay not able to detect the fault as continues 10 samples are not lies in the first zone of protection and hence no detection of fault. Similarly, for AB fault at $90 \%$ of line length results is shown in Figure 16 and the adaptive relay not mal-operate for overreaching the fault.

\section{CONCLUSIONS}

In this research work an accurate subsynchronous component based on SSSC controller with adaptive setting scheme to mitigate the SSR and its effect on distance protection of transmission line is reported.With the injection of series voltage in to the line using SSSC the adverse effect of SSR on turbine-generator is reduced to a great extent. In order to mitigate the effect of SSSC at middle of transmission line on distance protection an adaptive setting scheme is proposed. To change the reach of relay for various levels of compensation (series) a method of adaptive distance protection first zone setting is proposed. Adaptive distance protection setting factor is decreased for lower level of compensation and is increased for larger level of compensation. By comparing the conventional technique with proposed 
adaptive scheme, it is understand that, there is a noteworthy enlarge in the enclosed area by distance relay and the mal-operation of the distance relay in presence of SSSC has been overcome. The simulation results show the effectiveness of the proposed distance relay setting, the zone is increased adaptively and gives very accurate relay trip decision in presence of SSSC based SSR controller.

\section{Appendix A}

The study system parameter of IEEE first bench mark model, SSSC parameter and Bergeron model are given in Tables A.I-IV [1, 3, 4, 15, 16].

Table A.I Study System Network Parameters

\begin{tabular}{|l|c|c|}
\hline Resistance of power network & $\mathrm{R}_{\mathrm{L}}$ & 0.0113 p.u. \\
\hline Reactance of Transformer & $\mathrm{X}_{\mathrm{T}}$ & 0.142 \\
\hline Ratio of Transformation & & $22 / 539 \mathrm{kV}$ \\
\hline Reactance of line & $\mathrm{X}_{\mathrm{L}}$ & $0.50 \mathrm{p} . \mathrm{u}$. \\
\hline Reactance of Transmission line & $\mathrm{X}_{\text {sys }}$ & $0.08 \mathrm{p} . \mathrm{u}$. \\
\hline
\end{tabular}

Table A. II Parameters of Synchronous Machine

\begin{tabular}{|c|c|c|c|}
\hline Reactance & Value [p.u.] & Time constant & Value [sec] \\
\hline $\mathrm{X}_{\mathrm{a}}$ & 0.130 & $\mathrm{~T}_{\mathrm{d} 0}^{\prime}$ & 4.3 \\
\hline $\mathrm{X}_{\mathrm{d}}$ & 1.79 & $\mathrm{~T}_{\mathrm{d} 0}^{\prime \prime}$ & 0.032 \\
\hline $\mathrm{X}_{\mathrm{d}}^{\prime}$ & 0.169 & $\mathrm{~T}_{\mathrm{q} 0}^{\prime}$ & 0.85 \\
\hline $\mathrm{X}_{\mathrm{d}}^{\prime \prime}$ & 0135 & $\mathrm{~T}_{\mathrm{q} 0}^{\prime \prime}$ & 0.05 \\
\hline $\mathrm{X}_{\mathrm{q}}$ & 1.71 & & \\
\hline $\mathrm{X}_{\mathrm{q}}^{\prime}$ & 0.228 & & \\
\hline $\mathrm{X}_{\mathrm{q}}^{\prime \prime}$ & 0.200 & & \\
\hline
\end{tabular}

Table A. III Study System Shaft Parameters

\begin{tabular}{|c|c|c|c|}
\hline Inertia & $\mathrm{H}\left[\mathrm{s}^{-1}\right]$ & Shaft section & Spring constant [p.u. T/rad] \\
\hline Generator & 0.868495 & & \\
\hline LPB turbine & 0.884215 & LPB-GEN & 70.858 \\
\hline LPA turbine & 0.858670 & LPA-LPB & 52.038 \\
\hline IP turbine & 0.155589 & IP-LPA & 34.929 \\
\hline
\end{tabular}




\begin{tabular}{|l|l|l|l|}
\hline HP turbine & 0.092897 & HP-IP & 19.303 \\
\hline
\end{tabular}

Table A. IV SSSC parameters

\begin{tabular}{|c|c|c|}
\hline Rated power of converters & $\mathrm{P}_{\mathrm{VSC}}$ & $12.86 \mathrm{MVA}$ \\
\hline Rated Voltage of converters & $\mathrm{V}_{\mathrm{VSC}}$ & $8 \mathrm{kV}$ \\
\hline DC-link Capacitor & $\mathrm{C}_{\mathrm{dc}}$ & $15 \mu \mathrm{F}$ \\
\hline \multicolumn{2}{|c|}{ Controller parameters } \\
\hline Sampling frequency & $\mathrm{f}_{\mathrm{s}}$ & $1.4 \mathrm{kHz}$ \\
\hline Switching frequency & $\mathrm{f}_{\mathrm{sw}}$ & $660 \mathrm{~Hz}$ \\
\hline PLL bandwidth & $\alpha_{\mathrm{PLL}}$ & $16.62 \mathrm{rad} / \mathrm{sec}$ \\
\hline SSCC bandwidth & $\alpha_{\mathrm{cc}}$ & $9.96 \mathrm{rad} / \mathrm{sec}$ \\
\hline DCVC bandwidth & $\alpha_{\mathrm{dc}}$ & $12.25 \mathrm{rad} / \mathrm{sec}$ \\
\hline
\end{tabular}

The parameters of SSSC are given in Table A. IV $[9,10]$.

Table A. V Data of Study System shown in Fig.1.

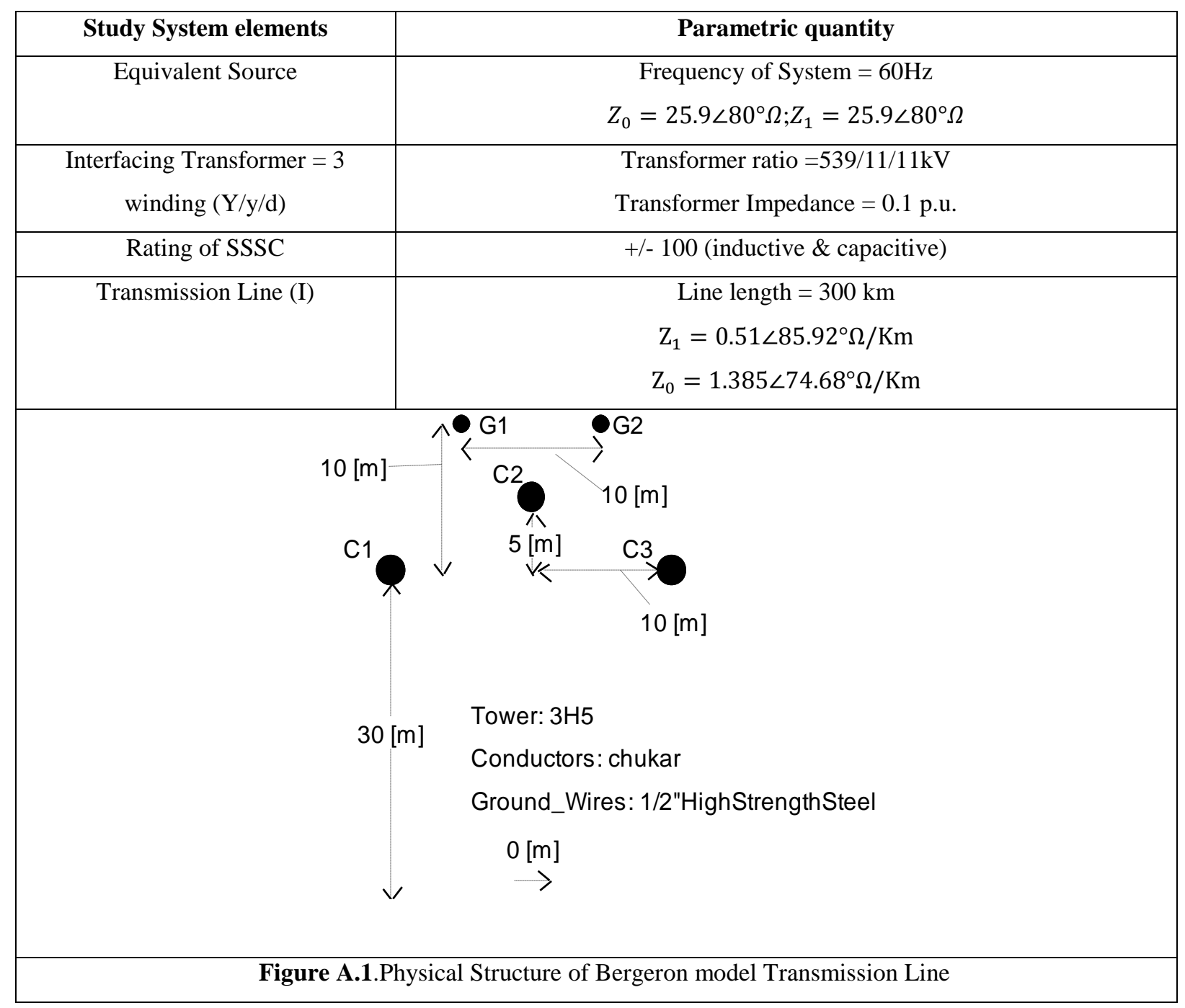


Figure.A.2. describes the algorithm of proposed Mho relay (Adaptive)for the protection of transmission line with SSSC. This is the modified version of the Mho relay (conventional) with the help of synchronized phasors measurement unit. The setting of Mho relay is made to protect $80 \%$ of transmission line 1 and is located at bus $P$ (sending-end). The distance relay at relay bus $P$ measures line current $\left(\mathrm{I}_{\mathrm{s}}\right)$ and phase voltage $\left(\mathrm{V}_{\mathrm{s}}\right)$ by using a current transformer (CT) and potential transformer (PT), respectively. The SSSC is positioned $100 \mathrm{~km}$ from the generator (sending-end) of line 1 at coupling bus $B_{l}$, which measures injected voltage $V_{\text {inj }}$ by SSSC. All measurements at bus $\mathrm{B}_{1}$ are transferred to bus $\mathrm{P}$ with the help of fiber-optic communication channel and are given to adaptive setting relay unit. In this unit, the equivalent impedance due to SSSC in the transmission line is computed and is a function of $\mathrm{V}_{\text {inj }}$ by SSSC. The communication channel consists of fiber-optic is simulated with the help of transmitter/receiver tools in PSCAD/EMTDC software.

\section{Suggested Adaptive Mho Relay Algorithm}

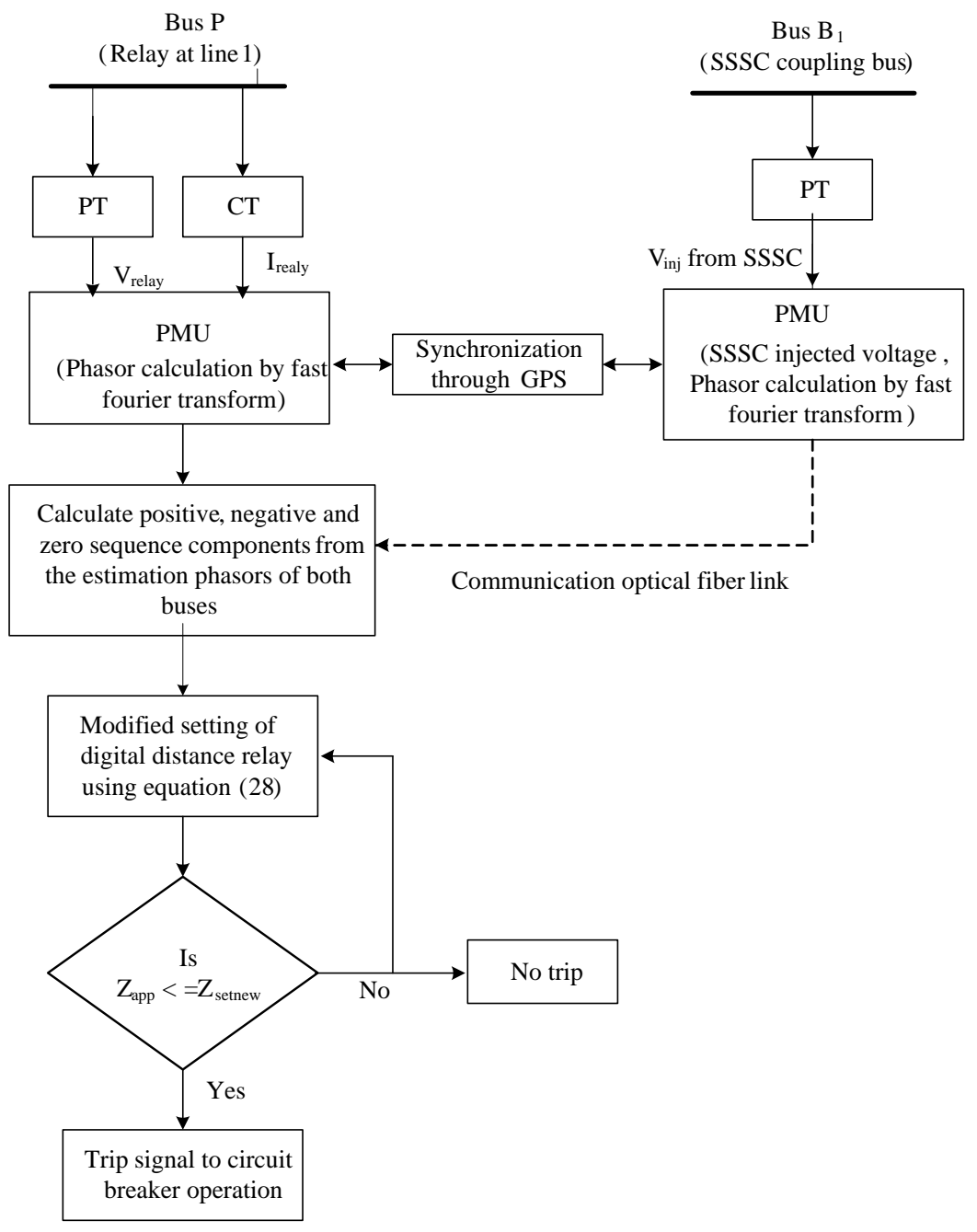

Figure A. 2 Adaptive algorithm of digital distance relaying 
Fault impedance $\mathrm{Z}$ ( $\mathrm{R}$ and $\mathrm{X}$ ) is computed and is modified with the help of adaptive procedure at the point of relay using sequence and fundamental components of the fault current and voltage signal. The transient current and voltage can be decomposed into the fundamental quantity using Fast Fourier transform, and the zero and positive -sequence value of voltage and current are obtained with the help of sequence filter [23-24].The proposed adaptive Mho relay algorithm changes the parameter of setting to adaptive for new compensation level and the fault is on the line, the relay issue proper command to circuit breaker by comparing the measured apparent impedance with the modified setting to clear faults.

\section{REFERENCES}

[1] Anderson P. M., Agrawal. B. L. \& Ness. J. V (1989). Subsynchronous Resonance in Power Systems. IEEE Press, New York.

[2] IEEE SSR Working Group. (1985). Terms, definitions and symbols for subsynchronous oscillations. IEEE Trans. Power Appl. Syst.(06):1326-1334.

[3] Padiyar K. R (1998) Analysis of sub-synchronous resonance in power systems. Springer.

[4] Kundur P (1994) Power system stability and control. McGraw Hill, New York, NY, USA.

[5] Cheng. T. C, Ning. T. S (1981). The Effect of Subsynchronus current on a Static Mho type Distance Relay. IEEE Trans. Power Apparatus and Systems, 100(11): 4562-4570.

[6] Hingorani N. G. \& Gyugyi. L (2000). Understanding FACTS: concepts and technology of flexible ac transmission systems. IEEE Press, New York.

[7] Varma. K Rajiv et al. (2008) Mitigation of Sub-synchronous resonance in a seriescompensated wind farm using FACTS controllers. IEEE Trans. Power Delivery, 23:1645-1654.

[8] Bongiorno M, Svensson J. \& Ängquist L (2008) Online estimation of Sub-synchronous voltage components in power systems. IEEE Trans. on Power Delivery23(01): 410418.

[9] Bongiorno M., Ängquist L. \& Svensson J (2008) A novel control strategy for subsynchronous resonance mitigation.IEEE Trans. on Power electronic, 23(02):735-743.

[10] Bongiorno M, Svensson J. \& Ängquist L (2008) Single-Phase VSC Based SSSC for Subsynchronous Resonance Damping.IEEE Trans. on Power Delivery,23(03):15441552

[11] R. Thirumalaivasan, M. Janaki and N. Prabhu, (2013) Damping of SSR Using Subsynchronous Current Suppressor With SSSC," in IEEE Trans.on Power Systems, 28(01): 64-74.

[12] D. Koteswara Raju, Bhimrao S Umre, Mohan. P. Thakre, M Rambabu and S.Chaitanya, (2016). Fractional-order PI based STATCOM and UPFC Controller to Diminish Subsynchronous Resonance. SpringerPlus, 05:1599, 1-20. 
[13] D. Koteswara Raju, Bhimrao S Umre, A S Jungahre and B Chitti Babu (2016). Improved Control Strategy for Subsynchronous Resonance Mitigation with Fractionalorder PI Controller. Int. Journal of Emerging Electrical Power Systems, 18: 1-10 - In Press.

[14] D. Koteswara Raju, Bhimrao S Umre, A S Jungahre and B ChittiBabu (2017) Mitigation of Subsynchronous Resonance with Fractional-order PI based UPFC controller. Mechanical Systems and Signal Processing, 85: 698-715.

[15] Anderson, P. M. (1998). Power System Protection. IEEE Power Engineering Society, IEEE Press.

[16] Phadke, A. G., Thorp, J. S (2009). Computer relaying for power systems. Wiley. Press.

[17] Thakre M. P. and Kale V. S (2014) Effect of static var compensator on the performance of digital distance relay protection of transmission line. The Journal of CPRI, 10(4).

[18] Khederzadeh M. and Ghorbani, A (2012) Impact of VSC-based multiline FACTS controllers on distance protection of transmission lines. IEEE Trans. on Power Delivery, 27(1); 32 -39.

[19] Sidhu, T. S, Varma R. K, Gangadharan, P. K., Albasri, F. A., and Ortiz G. R (2005). Performance of distance relays on shunt-FACTS compensated transmission lines. IEEE Trans. on Power Delivery, 20(3):1837-1845.

[20] El-Arroudi, E., Joos, G., and Mcgillis, D. T (2002) Operation of impedance protection relays with the STATCOM. IEEE Trans. on Power Delivery, 17(2): 381-387.

[21] Dash P. K., Pradhan A. K., and Panda G (2001).Apparent impedance calculations for distance-protected transmission lines employing series-connected FACTS devices.Electric Power Components and Systems, 29: 577-595

[22] Dash P. K., Pradhan A. K., Panda G, and Liew A. C (2000). Adaptive relay setting for flexible AC transmission systems (FACTS). IEEE Trans. on Power Delivery, 15(1): $38-43$.

[23] Manoi A., Tripathy M., and Gupta H. O (2014) Advance compensated mho relay algorithm for a transmission system with shunt flexible AC transmission system device. Electric Power Components and Systems, 42(16):1802-1810.

[24] Thakre M. P., and Kale V. S (2016).An adaptive approach for three zone operation of digital distance relay with static var compensator using PMU. Int. Journal of Electrical Power and Energy Systems, 77: 327-336.

[25] Albasri F. A., Sidhu T. S., and Varma R. K (2007) Mitigation of adverse effects of midpoint shunt-FACTS compensated transmission lines on distance protection schemes. In Power Engineering Society General Meeting, 2007. IEEE, pp. 1-8.

[26] Navalkar P. V. and Soman S. A (2011) Secure remote backup protection of transmission lines using synchrophasors. IEEE Trans. on Power Delivery, 26, (1):8796.

[27] Seethalekshmi K., Singh S. N. and Srivastava S. C (2012) A classification approach using support vector machines to prevent distance relay mal operation under power swing and voltage instability. IEEE Trans. on Power Delivery, 27(3):1124-1124.

[28] Apostolopoulos C. A., and Korres G. N (2012) Accurate fault location algorithm for double-circuit series compensated lines using a limited number of two-end 
synchronized measurements. Int. Journal of Electrical Power and Energy Systems, 42: 495-507.

[29] Jamali, S., Kazemi, A., \& Shateri, H. (2009). Modified distance protection in presence of SSSC on a transmission line. In Power \& Energy Society General Meeting, PES'09. IEEE, pp. 1-8.

[30] Jamali, S., Kazemi, A., \& Shateri, H. (2010). Adaptive distance protection in presence of SSSC on a transmission line. In Power System Technology (POWERCON), International Conference on, pp. 1-7.

[31] Ghorbani, A., Mozafari, B., \& Ranjbar, A. M. (2012). Digital distance protection of transmission lines in the presence of SSSC. International Journal of Electrical Power \& Energy Systems, 43(1), 712-719.

[32] Ghorbani, A., Ebrahimi, S. Y., \& Ghorbani, M. (2017). Active power based distance protection scheme in the presence of series compensators. Protection and Control of Modern Power Systems, 2(1), 7.

[33] Salemnia A., Khederzadeh M. \& Ghorbani A (2008) Mitigation of subsynchronous oscillations by 48-pulse VSC STATCOM using remote signal. IEEE Bucharest Power Tech, pp.1-7.

[34] Manitoba HVDC Research Centre, "PSCAD V4.2 electromagnetic transients program including dc system, 2003," Users Guide. 